\title{
TORMENTA ROMANA. ANÁLISIS MORFOLÓGICO Y FUNCIONAL DE LA ARTILLERÍA ROMANA TARDOREPUBLICANA EN EL NORDESTE PENINSULAR
}

\author{
TORMENTA ROMANA. MORPHOLOGICAL AND FUNCTIONAL ANALYSIS \\ OF LATE REPUBLICAN ROMAN ARTILLERY \\ IN NORTHEASTERN IBERIA
}

POR

\author{
EduARD Ble Gimeno*
}

\section{RESUMEN - ABSTRACT}

Este trabajo pretende estudiar el uso de la artillería romana en el nordeste de la Península Ibérica durante el período tardorepublicano (218 - 45 a.C.). Para ello se analizan las evidencias arqueológicas más abundantes y a la vez las menos estudiadas: sus proyectiles. Se propone una clasificación tipológica de los proyectiles en función de su calibre. Al mismo tiempo se plantea una caracterización funcional para cada uno de los hallazgos en función de su contexto arqueológico y su datación.

This paper pretends to study the use of Roman artillery in the northeast of the Iberian Peninsula during the Late Republican period (218 - 45 BC). I analyze the most abundant archaeological evidence, but also the least studied: the projectiles. I propose a typological classification based on their caliber. At the same time I suggest a functional characterization for each of the findings based on their archaeological context and dating.

\section{Palabras Clave - Keywords}

Artillería romana; período tardorepublicano; nordeste peninsular.

Roman artillery; Late Republican period; northeastern Iberia.

\section{INTRODUCCIÓN}

El presente artículo se encuadra dentro de un proyecto de tesis centrado en el análisis arqueológico de la presencia militar romana en el nordeste de la Península Ibérica, desde el desembarco de Cneo Cornelio Escipión en Ampurias en 218 a.C. hasta las guerras civiles entre César y los partidarios de Pompeyo a mediados del siglo I a.C. Al mismo tiempo, constituye una parte del trabajo final de máster (practicum) que presentamos (Ble, 2010), y que estaba dedicado al estudio de este tipo de armamento concreto: los proyectiles de artillería. De hecho, se trataba de una primera aproximación al tema, y para ello se eligieron unos materiales

\footnotetext{
* GRACPE, Universidad de Barcelona <eble@ub.edu>.
} 
casi nunca estudiados hasta hoy, pero de los cuales disponemos de un número significativo de ejemplares distribuidos por toda nuestra área de estudio.

Así pues, mi primer objetivo aquí es presentar el conjunto de proyectiles de artillería estudiados, muchos de los cuales permanecían aún inéditos, o en todo caso, no gozaban de un estudio sistemático más allá de su mera publicación. En primer lugar, se ha analizado el proceso que propició su deposición en el registro arqueológico, hecho que ha permitido afinar hasta cierto punto su cronología. A continuación, los proyectiles han sido objeto de un estudio morfológico en el cual se han aplicado algunos análisis estadísticos con el fin de elaborar una propuesta tipológica que tenga en cuenta tanto su cronología como su calibre. Finalmente, en base a su contextualización arqueológica, se plantea una hipótesis sobre su función en la antigüedad, ya fuera ésta ofensiva, defensiva, o incluso funeraria.

El trabajo se ha centrado en los proyectiles documentados en las ciudades de Ampurias (l'Escala, Girona) y Tarraco, el castellum de Puigpelat (Tarragona), y los oppida ibéricos del Castellet de Banyoles (Tivissa, Tarragona) y Burriac (Cabrera de Mar, Barcelona) (fig. 1), y combina la relectura de los diarios de excavación y la bibliografía referente a cada yacimiento, con el estudio directo de los materiales.

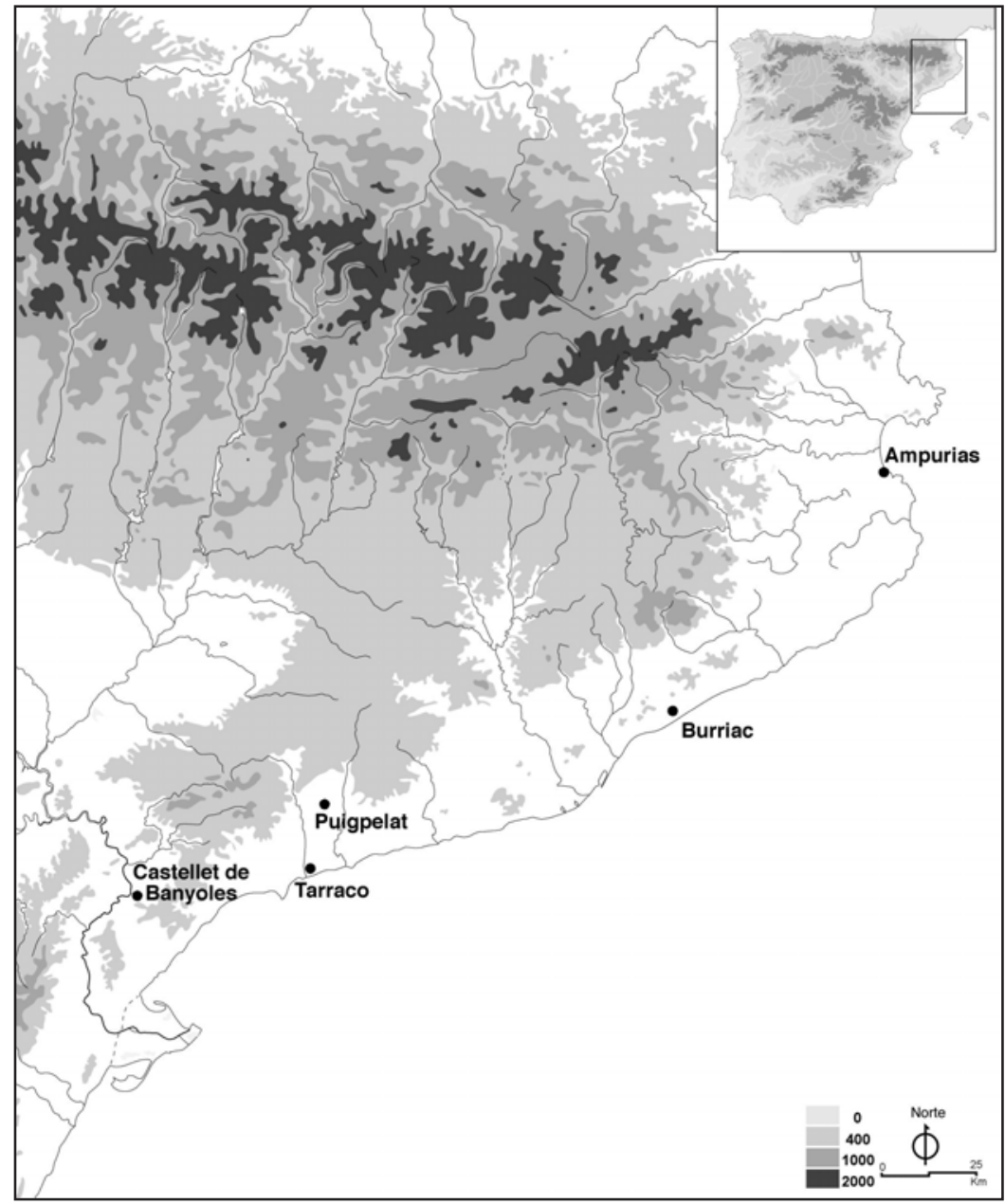

Figura 1. Mapa del nordeste de la Península Ibérica con la situación de los yacimientos estudiados. 


\section{ESTADO DE LA CUESTIÓN}

En cierto modo se puede afirmar que el interés por la artillería antigua se ha mantenido vivo, aunque con grandes variaciones en su intensidad, desde la misma antigüedad hasta nuestra fecha. Y de hecho, contamos con trabajos dedicados exclusivamente a este argumento desde mitades del siglo XIX ${ }^{1}$.

Aún así, es a finales de la década de los años 60 cuando podemos situar el nacimiento de esta disciplina. En este momento, y después de casi medio siglo de sequía a causa de las Guerras Mundiales, se retomaron los trabajos sobre la artillería antigua de la mano de E. W. Marsden. Sus obras Greek and Roman Artillery: Historical Development (1969) y Techincal Treatises (1971) plantean una línea evolutiva de la artillería de época clásica que a grandes rasgos permanece inalterada hoy en día. Su obra se ha convertido en el fundamento teórico de todos los trabajos posteriores y una referencia básica para la interpretación de los textos antiguos.

Desde el punto de vista arqueológico, el otro referente es sin duda D. Baatz, quien en poco más de una década dio a conocer infinidad de evidencias arqueológicas de artillería antigua, aumentando de forma exponencial los datos disponibles y haciendo patente su importancia a nivel cuantitativo y su dispersión geográfica por toda la mediterránea (Baatz, 1994 y 1999)².

Recientemente han aparecido nuevas obras de síntesis, como los trabajos de D. Campbell (2003 y 2006) o T. Rihll (2007), que presentan una visión diacrónica de la evolución de la artillería bastante completa y ponen en conjunción las fuentes literarias con los principales hallazgos arqueológicos. Su discurso histórico bebe en buena parte de E. W. Marsden, pero a la vez aportan nuevas propuestas interpretativas y abren líneas de investigación. Por su parte, F. Russo (2002 y 2004), con una clara formación como ingeniero, ha dado una importancia enorme a las innovaciones y la evolución tecnológica, junto con unas excelentes reconstrucciones tridimensionales de cada una de las máquinas documentadas.

Este nuevo interés por la materia ha ido ligado a la reactivación de la reconstrucción y la experimentación con máquinas a escala real. Justamente, en este campo disponemos en la península de varios investigadores especializados, como es el caso de R. Sáez, que reconstruyó la catapulta de Caminreal y posteriormente ha realizado muchas más reconstrucciones de diversas máquinas de guerra y de sitio de la antigüedad (Sáez, 2005), o el de A. Iriarte y su versión de la cheiroballista de Herón³.

\footnotetext{
1 Entre los que destacan Kochly, H. y Rustov, W. (1853): Griechische Kreigsschriftsteller, la primera obra dedicada a la artillería antigua; Wescher, C. (1967): Poliorcétique des grecs, la contrapartida francesa, basada aún sólo en los textos clásicos; Prou, V. (1877): La chirobaliste d'Heron d'Alexandrie, que tiene en cuenta ya la catapulta hallada en Lyon; Scheider, R. (1906): Herons Cheiroballistra o Schramm, E. (1918): Die Antiken Geschütze der Saalburg, Bad Homburg (reeditada por D. Baatz en 1980), que a partir de los restos descubiertos en Ampurias empezó a realizar las primeras reconstrucciones de máquinas de artillería.

2 La bibliografía de este trabajo no recoge la extensa producción de este autor por falta de espacio. Aún así consideramos muy útil la consulta de cualquiera de sus trabajos: Baatz, D. (1978): «Recent Finds of Ancient Artillery», Britannia, 9, 1-17, en que recoge los hallazgos de Hatra (Iraq), Orsova y Gornea (Hungría); Baatz, D. (1980): «Ein Katapult der legio IV Macedonica aus Cremona», Mitteilungen des Deutschen Archäologischen Instituts, Römische Abteilung, 87, 283-299; Baatz, D. (1982): «Hellenistische Katapulte aus Ephyra (Epirus)», Mitteilungen des Deutscher Archäologischen Instituts, Athenische Abteilung, 97, 211-233; Baatz, D. (1985): «Katapultteile aus dem Schiffswrack von Mahdia (Tunesien)», Archäologische Anzeiger, 679-691; Baatz, D. (1988a): «Eine Katapult - spannbusche aus Pytius, Georgien (UDSSR)», Saalburg Jahrbuch, 44, 59-64; Baatz, D. (1988b): B. Cunliffe (ed.), The Temple of Sulis Minerva at Bath: Vol. 2 The Finds from the sacred Spring, Oxford University Press, 7-9; Baatz, D. (1994a): «Eine Katapult - spannbuschen von Auerberg», G. Ulbert (ed.), Der Auerberg, München, 173-187; Baatz, D. y Feugère, M. (1981): «Eléments d'une catapulte romaine trouvée à Lió», Gallia, fouilles et monuments archéologiques en France métropolitaine, Paris, 201-209.

3 No incluimos sus trabajos en nuestra bibliografía debido a que éstos se centran en la cheiroballistra, un tipo de catapulta con una problemática específica que se aleja de nuestro objetivo. Aún así, merecen ser mencionados: Iriarte Kortazar, A. (2000): «Pseudo-Heron's chieroballistra a(nother) reconstruction: I. Theoretics», A.T. Croom and W.B. Griffiths
} 
En referencia al estudio de los proyectiles de artillería, la bibliografía es aún más reducida. En el caso de los lithoboloi, el interés de los investigadores se ha centrado principalmente en establecer los diferentes calibres de ballistae a partir del peso de sus proyectiles. Este tipo de estudio tiene su máxima expresión en los conjuntos documentados en yacimientos del oriente mediterráneo como Salamis (Chipre), Rodas, Pérgamo o Tel Dor (Siria), donde los proyectiles presentaban grabados que permitían clasificarlos según sus calibres mediante sistemas de tipo alfabético o acrofónico (Campbell, 2003: 18-22).

En el caso de los pila catapultaria, el interés ha sido aún menor y el trabajo se ha limitado hasta hace poco a constatar su hallazgo, y como mucho a documentar las medidas y el peso. Curiosamente, el reciente interés hacia los pila catapultaria no surgió de entre las filas de los estudiosos de la artillería sino de entre aquéllos más interesados en la panoplia guerrera. Así, a principios de los años 90, empezamos a encontrar unos primeros intentos de sistematización en las obras generales de M. C. Bishop y J. C. N. Coulston (1993), Roman Military Equipment, y de M. Feugère (1993), Les armes des romains: de la République à l'Antiquité tardive. El segundo, poco después, publicó un trabajo mucho más exhaustivo dedicado exclusivamente a la Galia, y donde también realizó un estudio estadístico pionero de los proyectiles líticos (Feugère, 1994).

Posteriormente, S. Sievers ha continuado su trabajo en torno a los pila catapultaria. En su estudio de los materiales de Osuna presenta la primera tipología en la que diferencia hasta 3 tipos distintos de puntas (Sievers, 1997), una clasificación mejorada en la publicación de los materiales de Alesia, (Sievers, 2001: 169-172). En último lugar, M. Poux, con la aplicación de análisis estadísticos muy básicos, ha conseguido establecer unos criterios numéricos para diferenciar los proyectiles tardorepublicanos de los altoimperiales (Poux, 2008: 354-358).

\section{ESTUDIO ARQUEOLÓGICO DE LAS EVIDENCIAS DE ARTILLERÍA}

Centrándonos ya en el estudio formal de los proyectiles objeto de nuestro trabajo, presentamos, en primer lugar, una breve relación de las piezas conocidas hasta la fecha y su estado de conservación actual, para posteriormente pasar a discutir su contextualización estratigráfica con el fin de otorgarles una datación lo más concreta posible.

\section{AMPURIAS}

La mayor parte de los proyectiles estudiados proceden del complejo arqueológico de Ampurias, aunque aparecieron en distintas áreas del yacimiento formando diversos conjuntos, comúnmente llamados «lotes». El primero, y también el más abundante, lo encontró E. Gandia cerca de la muralla meridional de la neápolis, entre el 28 y el 30 de agosto de 1911. En esta ocasión, y según describe él mismo en sus diarios de excavación, se localizaron los restos de lo que posteriormente se identificaría como el capitulum de una catapulta, juntamente con 1406 glandes de plomo, 54 puntas de pila catapultaria y un proyectil lítico.

Actualmente se conservan 36 proyectiles de catapulta en la sede del Museu d'Arqueologia de Catalunya (MAC) en Barcelona y 9 más en Ampurias. Aunque J. Brugada (1991: 23-36) documentó un total de 11 en la segunda, sólo hemos podido encontrar 10 piezas, y una de ellas ha sido descartada por tratarse, a nuestro juicio, de una punta de jabalina. Respecto al nivel

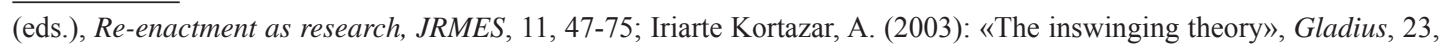
111-140. 
de conservación, hay que tener en cuenta que a principios del siglo XX, las puntas fueron totalmente recubiertas con cera endurecida, que aún conservándolas intactas, actualmente hace imposible conocer su forma exacta y tomarles medidas de forma precisa.

También se conserva un posible proyectil lítico, supuestamente descubierto junto con la catapulta, pero que no parece corresponderse con el que cita E. Gandia, ya que ése era bastante más grande: según su testimonio medía $60 \mathrm{~cm}$ de circunferencia y $17 \mathrm{~cm}$ de diámetro, mientras que el que hallamos mide $5,6 \times 7,1 \times 7,4 \mathrm{~cm}$.

En relación a la ubicación del hallazgo, en sus diarios de excavación E. Gandia escribió que el lote de la catapulta se encontró en una de las estancias anexas a la torre oriental de la muralla meridional de la neápolis griega, en concreto «a 17 metros desde la cara $\mathrm{S}$. de la muralla griega lado Este de la puerta y a 8 desde la cara Este del muro que arranca desde el lado $\mathrm{O}$ de la puerta y va de $\mathrm{S}$. a N.» [sic] $]^{4}$ Así pues, el conjunto de armamento no se encontró directamente en el interior de la muralla, como en ocasiones se ha afirmado, sino en una habitación anexa a ésta.

La mayoría de los proyectiles y la catapulta aparecieron dispersos sobre un pavimento, cubierto por un nivel de derrumbe con grandes bloques de piedra procedentes de los muros caídos de la habitación. Los restos aparecieron junto con los siguientes fragmentos de cerámica: «uno de clase saguntina con marca [SE] otro, encarnado formando escamas tres griegos fondo negro, uno ibero insignificante $[. .].\rangle^{5}$. Barro saguntino era un apelativo para la terra sigillata muy corriente a principios del siglo XX, y el fragmento encarnado seguramente hace referencia a uno de paredes finas con barbotina ${ }^{6}$.

Respecto al sello, desgraciadamente no hemos conseguido identificar la referencia de E. Gandia con ninguno en concreto. El único sello SE que hemos encontrado, con una cronología de 40-20 a. C., no parece corresponderse con ella, ya que su cartela presenta una forma floral inexistente en la reproducción que aparece en los diarios ${ }^{7}$.

Existiría la opción que la marca fuera incompleta, lo que abriría mucho el abanico de posibilidades, pero esta hipótesis tampoco parece adecuarse mucho a su dibujo.

De todos modos, el hecho de que se documente un fragmento de terra sigillata nos sitúa cronológicamente, como mínimo, en un momento a partir del reinado de Augusto. El estrato de nivelación inferior no contenía ningún fragmento de terra sigillata, y en cambio, las cerámicas de importación se limitaban al barniz negro. Por tanto, en contraposición, podemos fecharlo en época republicana.

Si entendemos la catapulta tuvo que ser concebida forzosamente para ser instalada sobre la muralla, la datación de su construcción en torno a 150 a.C. (Sanmartí y Nolla, 1986) nos es útil como terminus post quem del inicio del uso de la máquina. Esto, sumado al hecho de que la amortización de la habitación se produjo en época augustal, nos permite, aunque con cierta falta de precisión, disponer de un primer marco cronológico, que se extiende entre la segunda mitad del siglo II y la primera mitad del siglo I a.C., en el que colocar su uso.

Además de este conjunto, durante la excavación de la necrópolis de Les Corts, a finales de la década de 1920, aparecieron otros proyectiles. Podemos identificar en los dibujos de M. Almagro (1953: 276 y 378) dos puntas de pila catapultaria en la tumba 3 y otra en la tumba

\footnotetext{
4 Cita procedente del diario personal de Emili Gandia, año 1911, p. 163. Aprovechamos la ocasión para agradecer a Marta Santos, Pere Castanyer y Joaquim Tremoleda del MAC Empúries la posibilidad de consultar tanto los diarios como los materiales depositados en el museo, así como por su atención y disposición durante nuestra estancia en él.

5 Vid nota 4, p. 168.

6 Información proporcionada por Marisol Madrid a la que agradecemos su útil orientación en este aspecto.

7 La firma és la núm. 1832 de Oxe, A., Comfort, H. y Kenrick, Ph. (2000): Corpus Vasorum Arretinorum. A catalogue of the Signatures, Shapes and Chronology of Italian Sigillata, $2^{\mathrm{a}}$ ed., Bonn.
} 
156 (fig. 2). Sólo la última se conserva actualmente, y también sólo ésta aparece en el trabajo de J. Brugada (1991: 55-60). Su datación resulta realmente complicada, pues la vida de esta necrópolis se extiende a lo largo de los siglos II y I a.C., y ninguna de las dos tumbas dispone de más restos materiales que las propias puntas y una urna cineraria hecha a mano en el caso de la tumba 3, lo cual no permite afinar más la cronología a través de otras evidencias arqueológicas.

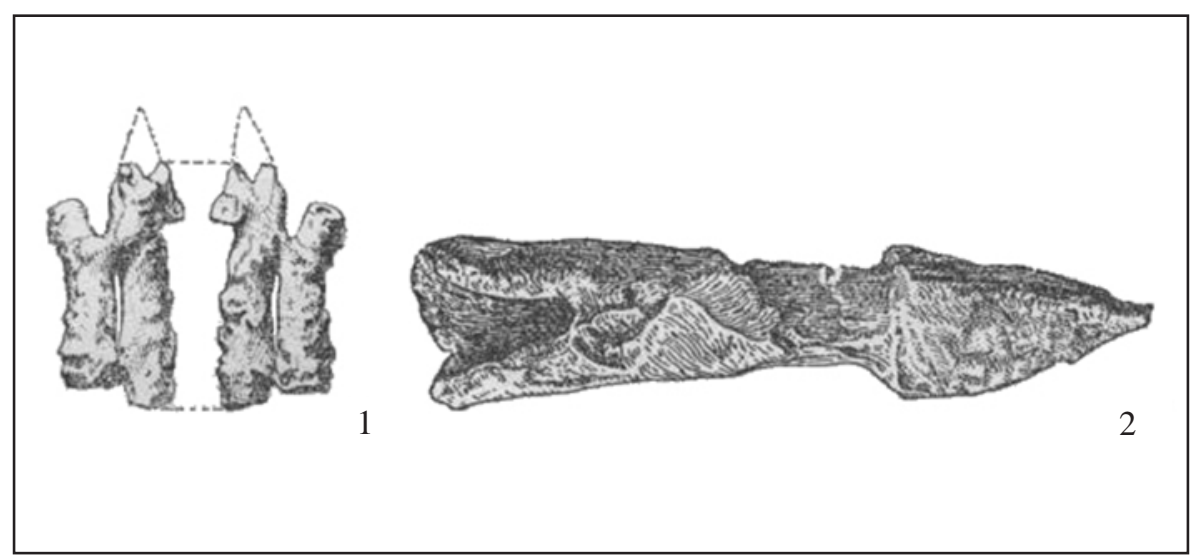

Figura 2. Dibujos de los pila catapultaria procedentes de la necrópolis de Les Corts (Ampurias) a escala 1:3 (extraídos de Almagro, 1953: 276 y 378). (1) Incineración 3. (2) Incineración 156.

A los proyectiles ya mencionados debemos añadir otro pilum catapultarium aparecido en la escombrera de la necrópolis Martí y documentado por J. Brugada (1991: 49-50). Si nos centramos en su datación, la información disponible es muy reducida. Los niveles en que se encontró el proyectil son posteriores al uso de este espacio como necrópolis y se datan en torno a los siglos II - I a.C. No obstante, resulta interesante la mención que hace M. Almagro (1947-48: 321-322) al hallazgo de un tesoro monetario formado por siete ases, tres de ellos romanos y los otros cuatro de Indika, y que se puede situar sin problemas en la primera mitad del siglo II a.C.

Finalmente, disponemos de dos dardos más, procedentes de la excavación del párking de los años 80. Uno apareció en el interior de un gran edificio que perduró durante todo el siglo II a.C., depositado encima de uno de los pavimentos de opus signinum que se documentaron en este ámbito. El otro, en cambio, se localizó en una necrópolis griega de los siglos IV y III a.C. En concreto apareció junto a una posible incineración documentada a partir de una gran mancha de ceniza (Sanmartí y Nola, 1983-1984: 123). Personalmente, pensamos que esta atribución presenta serios problemas, ya que este proyectil es morfológicamente muy similar al resto, que son claramente romanos por cronología. Además, el hecho de que hasta ahora no se tenga conocimiento en la península de ninguna evidencia de artillería previa a la Segunda Guerra Púnica lo hace improbable. Aún así, es obvio que cualquier presunción histórica es susceptible de ser rebatida por la evidencia arqueológica, y en este sentido, el yacimiento griego de Ampurias parece ser el más favorable.

En el caso que este proyectil datase realmente de este período, constituiría la evidencia de artillería más antigua documentada en la península. En favor de esta posibilidad hemos de tener en cuenta que la fase de la muralla previa a las reformas del 150 a.C., datada del siglo IV a.C., ya presentaba evidencias de un amplio conocimiento poliorcético, con la construcción de 
un gran bastión en el ángulo suroeste de la muralla que protegía el acceso a la ciudad a través de una entrada en codo. Las grandes dimensiones de esta estructura y su posición destacada respecto al lienzo de la muralla, por tanto, son coherentes con la presencia de máquinas de artillería en su interior.

\section{TARRACO}

Durante una excavación arqueológica de urgencia en la plaça dels Àngels, entre el otoño de 1990 y la primavera de 1991, se localizaron en Tarragona 5 pila catapultaria (fig. 3). Disponemos de esta información gracias al testimonio de Jordi López, investigador del Institut Català d'Arqueologia Clàssica (ICAC), que tomó una fotografía de las piezas ${ }^{8}$. Desgraciada-

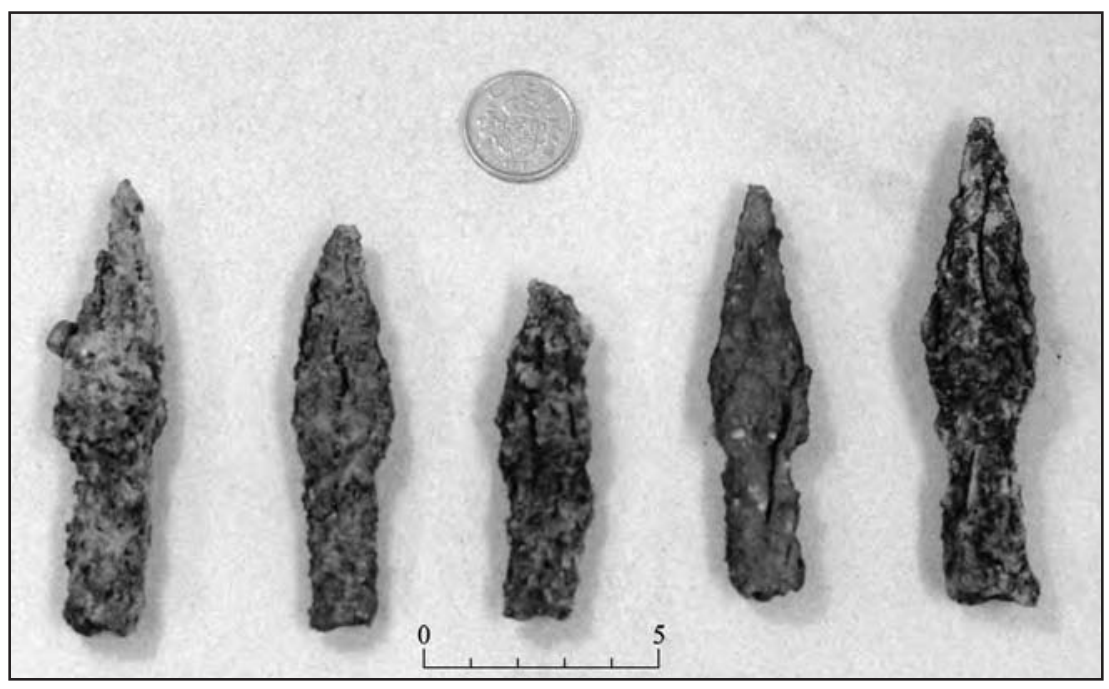

Figura 3. Fotografía de los pila catapultaria aparecidos en la plaça dels Àngels de Tarragona (cedida por J. López).

mente, no aparecen en el inventario de la memoria de excavación ni en la posterior publicación (Güell, 1993), tampoco consta su depósito en el Museu Nacional d'Arqueologia de Tarragona, y evidentemente ha resultado imposible encontrarlas.

Esta intervención tuvo como resultado la localización de niveles arqueológicos de época republicana, previos a las reformas que se llevaron a cabo para construir el Foro Provincial. Aunque el registro estratigráfico fue exhaustivo, desconocemos en qué UE aparecieron los proyectiles. Sólo sabemos que aparecieron en los estratos inferiores de época republicana que cubrían la roca natural, por lo que es muy probable su datación entre los siglos II y I a.C.

Lo que sí resulta interesante es el lugar en que aparecieron los proyectiles, muy próximos a la muralla republicana, y por lo que parece, también a una antigua puerta de la ciudad, actualmente desaparecida, pero que se situaría entre las calles Portella y Passeig de Sant Antoni, a sólo unos 30 m. de la excavación (Martín y Rovira, 2009: 16).

8 Agradecemos a Jordi López que tomara dicha fotografía y el hecho de que nos la cediera. Si no fuera por ello no quedaría ninguna evidencia del hallazgo de estos proyectiles. 
Por tanto, si queremos proponer una cronología para los proyectiles, lo más lógico sería relacionarlos con la fecha de construcción de la muralla, a la que seguramente estarían vinculados. Esta datación ha suscitado un amplio debate, que aún se mantiene abierto. En efecto, algunos investigadores han defendido que todo el perímetro de la muralla fue construido en una única fase, fechada en la primera mitad del siglo II a.C. (Sánchez Real, 1986; Díaz, 1999: 123).

Aún así, en general se ha aceptado la existencia de dos fases constructivas diferenciadas. La primera, coincidiría con la fosilización en piedra del primitivo praesidium hacia principios del siglo II a.C. (Vegas, 1986) o incluso finales del siglo III a. C. (Járrega, 2004: 26-29), y se limitaría a las tres torres hoy conservadas: la de Minerva, el Cabiscol, y el Arquebisbe, y dos lienzos de muralla entre la torre de Minerva y la del Cabiscol, y entre la del Arquebisbe y el Baluart de Santa Bàrbara (Palmada, 2003: 18-19). La segunda, en cambio, se dataría en torno al tercer cuarto del siglo II a.C. (Aquilué y Dupré, 1986; Járrega, 2004: 29-33), destaca por no disponer de ninguna torre, y correspondería al resto de lienzos que hoy en día se conservan (entre ellos el tramo de muralla donde se localizaron los proyectiles).

Recientemente, D. Hourcade ha realizado una revisión de las memorias de excavación de T. Hauschild que le permite defender de nuevo la hipótesis de una sola fase ${ }^{9}$. En nuestro caso, sea cual sea la interpretación de la muralla que aceptemos, la datación del sector de muralla más cercano a los proyectiles permanece invariable en torno a 150 a.C. Esto nos permite establecer un terminus post quem, idéntico al que ya se proponía para Ampurias.

Por otro lado, durante las excavaciones de la torre de Minerva llevadas a cabo por T. Hauschild (1984-1985: 20-21), se documentaron dos troneras, una en el lado occidental y la otra en el septentrional. Ambas fueron interpretadas como orificios para artillería, basándose en la altura del parapeto, a $0,76 \mathrm{~m}$ sobre el antiguo suelo de la torre, y en el desplazamiento de la base de un pilar respecto al centro de la torre, que se explicaría por la necesidad de ese espacio para colocar dos máquinas.

Así pues, vemos como también en el caso de Tarraco hay suficientes evidencias para afirmar que la muralla de la ciudad habría dispuesto de catapultae, por lo que es plausible plantear su existencia a partir de mediados del siglo II a.C. En este sentido, desconocemos si el praesidium que se instaló previamente durante la Segunda Guerra Púnica también dispondría de ellas, pero en cualquier caso parece que, tan pronto como las murallas se construyeron en piedra, se acondicionaron para acoger máquinas de artillería.

\section{Puigpelat}

Como resultado de una intervención arqueológica de urgencia en el municipio de Puigpelat en el año 2009, se identificó un yacimiento romano que ha sido caracterizado como un castellum. Su función militar se deduce por el tipo de arquitectura, con un sistema de defensa complejo, y por el hallazgo de diversos restos de armamento y otros materiales relacionados con tropas romanas, entre los cuales, tres posibles proyectiles de artillería líticos (Díaz, 2009: 39-58).

En este yacimiento se distinguieron dos fases diferenciadas, aunque sólo se excavó en extensión habitaciones pertenecientes a la más reciente, el castellum propiamente dicho. Todos los bolaños aparecieron en niveles pertenecientes a ésta segunda fase, aunque con cronologías diferentes. Uno de ellos apareció en los niveles de construcción del castellum, concretamente

9 Datos presentados de forma verbal en la comunicación «La muraille et la guerre: la première phase de l'enceinte de Tarragone en question» en el marco del congreso La guerre et ses traces. Conflits et sociétés en Hispanie à l'époque de la conquête romaine (III $-I^{e r}$ S. av. J.-C.) celebrado en Bordeaux (Francia) entre el 25 y el 27 de noviembre de 2010. 
en el relleno de un recorte del terreno paralelo a los muros de la fortificación, que habría funcionado como fossa del recinto superior. Los otros dos proyectiles se localizaron en los niveles de destrucción del castellum, pero desconocemos en qué punto exacto del yacimiento.

La construcción de la segunda fase se data a principios del siglo I a.C., y su abandono, poco antes del cambio de era, en torno a 10 a.C., lo que nos permite afirmar la existencia de alguna ballista a lo largo de este siglo. También se documentan materiales anteriores, de entre finales del siglo III y principios del II a.C., que apuntan hacia un inicio de la ocupación del yacimiento en esas cronologías, con la construcción del primer edificio, aunque su carácter militar no está probado para este momento inicial (Díaz, 2009: 85-89 y 110-115).

\section{El Castellet de Banyoles}

Otro de los conjuntos más importantes de proyectiles de artillería se halló en el yacimiento del Castellet de Banyoles, durante las excavaciones de las torres pentagonales. En concreto, en la torre sur, excavada en 1930 por L. Brull, apareció un número indeterminado de proyectiles líticos esféricos de unos $8 \mathrm{~kg}$ de peso, junto con proyectiles de honda, tanto de plomo como de piedra (Bru, 1955: 58).

A través de la correspondencia personal de su director, es posible conocer el hallazgo con más exactitud: «pedres de mà i de fona, glans de plom, dards de ferro projectils grossos de pedra arrodonits» $[\mathrm{sic}]^{10}$. De nuevo, no se especifica su número, pero sí las medidas de los proyectiles de ballista, con una masa de entre 8 y $9,5 \mathrm{~kg}$, y unos $60 \mathrm{~cm}$ de circunferencia. Los materiales fueron depositados en la sede del MAC en Barcelona y constan como tal en el registro de entrada. Desgraciadamente, en la actualidad no se conserva ningún rastro.

En otro documento, referente a las excavaciones de los años 40 , se produjo otro hallazgo mientras se realizaban tareas de «movimientos de tierra» para dejar a la vista la torre norte. En esta ocasión: «en cuantitat molt o considerable, [...] s'han recullit 4 «glandes» de plom, [...] pedres de fona, i una pedra grossa arrodonida com altres trobades anteriorment d'un pes de 8 a 9 quilos, que he donat en suposar que si seran de catapulta» [sic] ${ }^{11}$ Por la descripción del hallazgo podemos suponer que éste se produjo en el exterior del recinto del poblado, posiblemente en el área situada entre la torre y la vertiente norte del Castellet de Banyoles.

La única pieza que sí hemos podido encontrar ha sido una punta de pilum catapultarium conservada en el Museu d'Arqueologia Salvador Vilaseca de Reus (Tarradell-Font y Noguera, 2009: 148) (fig. 4). Aún así, el proyectil corresponde a un hallazgo independiente, procedente de las campañas de excavación de los años 1946 y 1947 en un sector al suroeste de la torre sur (Vilaseca et al., 1949: lám. XXXV, 1). Desconocemos en qué ámbito se encontró, pero sabemos que en el área se documentaron extensos niveles de ceniza.

Por este motivo, es difícil otorgarles ningún tipo de cronología basada en su contexto arqueológico. Ésta se plantea en función de la datación de las torres pentagonales, y sobre todo la destrucción generalizada y homogénea del yacimiento que evidenciarían los niveles de cenizas y a los cuales se vincularían los proyectiles. Hemos decidido dejar la cuestión de la datación de estos proyectiles para la última parte del trabajo dada su estrecha conexión con la función que se les atribuye y la interpretación que se da a todo el complejo defensivo del yacimiento.

10 Cita procedente de una propuesta de compra del terreno afectado por el yacimiento del Castellet de Banyoles realizada por L. Brull al Servei d'Excavacions de la Direcció del Patrimoni Artístic, Històric i Científic de la Generalitat de Catalunya. Documento recogido, junto con el resto de su correspondencia, por su sobrino Adolf Brull, al que agradecemos nos facilitara su consulta.

11 Cita procedente de una carta enviada por L. Brull a S. Vilaseca el 10 de septiembre de 1943. 


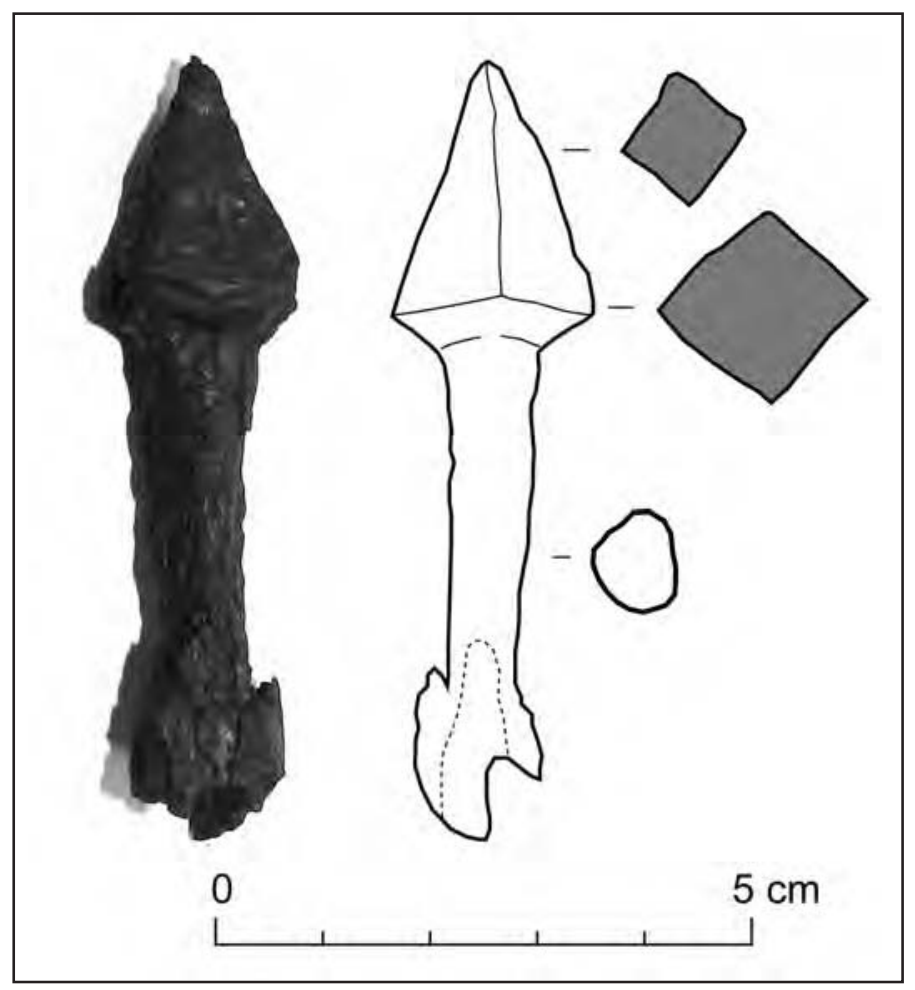

Figura 4. Dibujo y fotografía del pilum catapultarium encontrado en Castellet de Banyoles en la zona Vilaseca (extraídos de Tarradell-Font y Noguera, 2009: 148, fig. 4.3).

\section{BURRIAC}

Durante las campañas de excavación del yacimiento de Burriac de 1969-70 y 1970-71, aparecieron dos nuevas puntas de proyectil de catapulta. Aún así, sus excavadores, J. Barberà y R. Pascual, los clasificaron como pila convencionales. Su correcta atribución se produjo a raíz de un reestudio posterior de los materiales (Álvarez y Cubero, 1999: 133, nota 18). Las piezas fueron depositadas en el MAC, donde permanecen hoy en día en avanzado estado de degradación (fig. 5).

Uno de los proyectiles apareció dentro del llamado «edificio público», sector que se encuentra junto a la muralla oriental del poblado, concretamente en un estrato de colmatación de una estructura posterior que se construyó encima. Esta habitación se interpreta como un espacio de vivienda, ya que se documentó un nivel de uso relacionado con un hogar. Su construcción se sitúa en la segunda mitad del siglo II a.C., mientras que su amortización se data en torno al primer tercio del siglo I a.C.

El otro se encontró en un almacén de dolia situado en el lado meridional del yacimiento, concretamente en una habitación anexa. Su cronología responde a unos esquemas similares, con un uso que va de la segunda mitad del siglo II a.C. al segundo cuarto del siglo I a.C. (Barberà y Pascual, 1979-1980: 208-236; Zamora, 2006-2007: 88-111). Cabe destacar que este almacén se encuentra relativamente cercano a la puerta meridional, construida también en la segunda mitad del siglo II a.C. en un aparejo próximo al opus quadratum. 


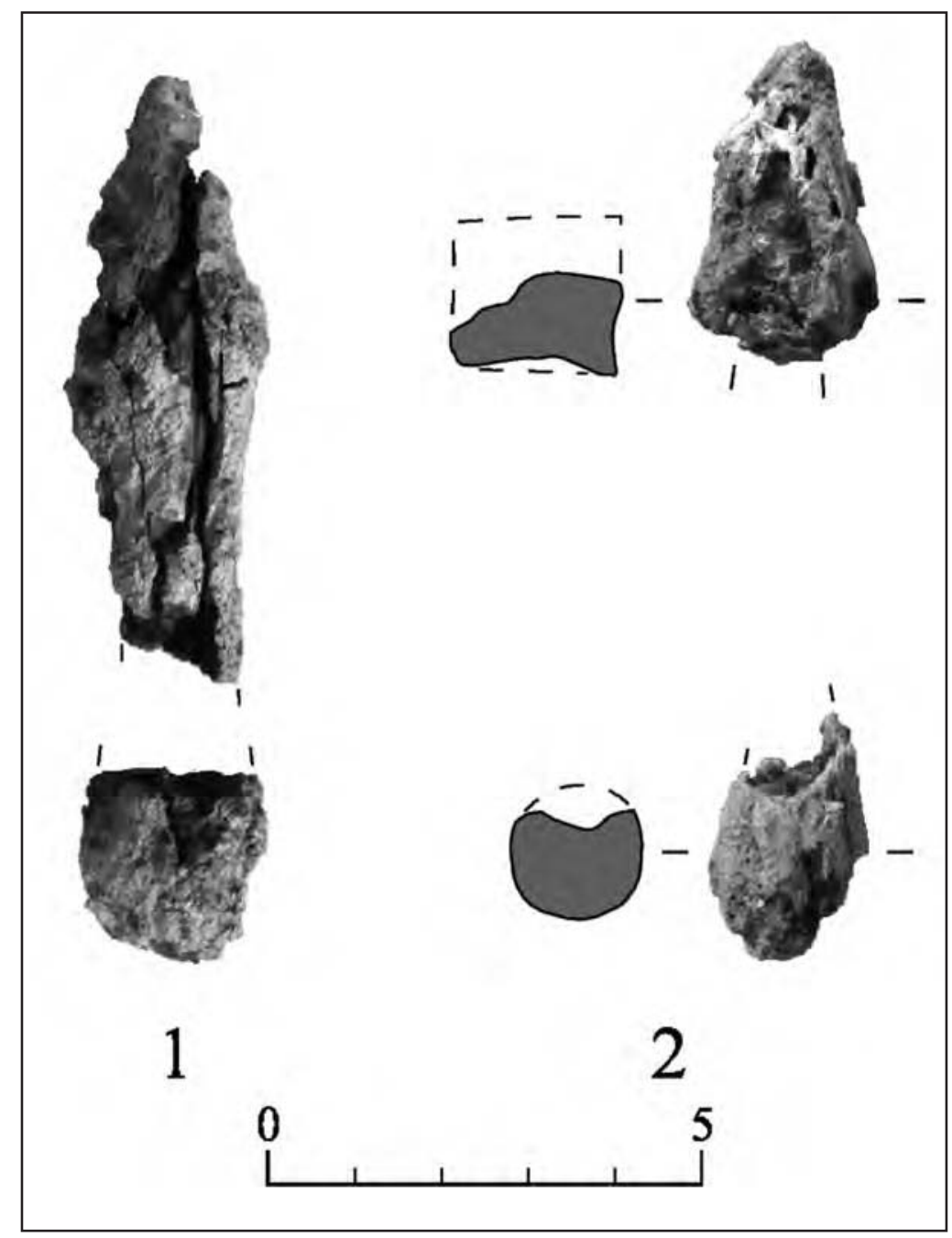

Figura 5. Dibujo y fotografía de los pila catapultaria encontrados en Burriac (realizados por el autor).

Ambos edificios pertenecen a una de las últimas fases del poblado, durante la cual se inician una serie de reformas por todo el yacimiento que incluyen la ampliación del área edificada a costa de espacios que hasta entonces se habían mantenido libres. Este crecimiento urbanístico lo podemos relacionar con la aparición de un nuevo barrio extramuros en la ladera de la montaña, en la zona de Ca l'Arnau-Can Mateu. Aquí se ha localizado un conjunto de casas de fuerte influencia latina: presencia de tegulae, pavimentos de opus signinum y una cloaca, además de un alto porcentaje de importaciones itálicas. Incluso se han documentado unas termas, edificio que implica la presencia de población romana conviviendo con los indígenas (Martín, 2004). 


\section{ESTUDIO MORFOLÓGICO DE LOS PILA CATAPULTARIA DE AMPURIAS}

A continuación presentamos el análisis morfológico de los proyectiles. Inicialmente pretendíamos analizar todo el conjunto de pila catapultaria, para poder explicar su variación tanto a nivel cronológico como geográfico, y determinar así si existían diferencias en función de su uso. Desgraciadamente, algunos de los proyectiles se han conservado en un estado tan fragmentario que no han permitido su manipulación, como por ejemplo los de Burriac, o simplemente no han aparecido, como en los casos de Tarraco o el Castellet de Banyoles. Por este motivo, se ha decidido trabajar exclusivamente con el conjunto coherente que conformaban los proyectiles de Ampurias, con piezas procedentes de contextos muy heterogéneos: tanto de dentro como de fuera del perímetro de la muralla e incluso de una necrópolis.

\section{SELECCIÓN DE VARIABLES Y ANÁLISIS DESCRIPTIVO}

Las medidas escogidas han tenido en cuenta su forma particular y característica, que geométricamente se puede simplificar en una punta maciza de forma de piramidal cuadrangular unida a un tubo de enmangue en forma de cono truncado por su parte estrecha. Así pues, éstas han sido la longitud de la punta (LP) y la del tubo (LT), la suma de las cuales produce la longitud total del proyectil, la anchura máxima de la punta (A), los diámetros mínimo (Dmin) y máximo (DMax) del tubo, el diámetro interior (Dint) del agujero de enmangue, su profundidad (P) y la masa total (M) (fig. 6).

Figura 6. Tabla de medidas de los pila catapultaria procedentes de Ampurias.

\begin{tabular}{|c|c|c|c|c|c|c|c|c|}
\hline Núm. inv. & $\mathbf{L P}(\mathbf{c m})$ & $\mathbf{L T}(\mathbf{c m})$ & $\mathbf{A}(\mathbf{c m})$ & $\begin{array}{c}\text { DMax } \\
\mathbf{( c m})\end{array}$ & $\begin{array}{c}\text { Dmin } \\
\mathbf{( \mathbf { c m } )}\end{array}$ & $\begin{array}{c}\text { Dint } \\
\mathbf{( c m})\end{array}$ & $\mathbf{P}(\mathbf{c m})$ & Masa (g) \\
\hline $\mathbf{1}$ & 3,4 & 9,7 & 2,7 & 2,7 & 1,8 & 1,3 & 5,1 & 155,5 \\
\hline $\mathbf{2}$ & 3,6 & 8,6 & 2,6 & 2,9 & 1,9 & 1,3 & & 149,5 \\
\hline $\mathbf{3}$ & 3,9 & 8,2 & 2,6 & 2,8 & 1,9 & 1,3 & 4,7 & 232,2 \\
\hline $\mathbf{4}$ & 4,5 & 8,6 & 2,9 & 2,8 & 2,0 & 1,3 & 5,8 & 144,1 \\
\hline $\mathbf{5}$ & 4,1 & 7,9 & 2,6 & 3,0 & 1,5 & 1,3 & 2,7 & 138,0 \\
\hline $\mathbf{6}$ & 3,5 & 6,9 & 2,4 & 2,8 & 1,8 & 1,3 & 3,8 & 107,7 \\
\hline $\mathbf{7}$ & 3,7 & 6,5 & 3,2 & 2,8 & 1,8 & & & 154,1 \\
\hline $\mathbf{8}$ & 3,8 & 8,6 & 2,8 & 2,9 & 1,7 & 1,3 & 2,8 & 161,3 \\
\hline $\mathbf{9}$ & 3,5 & 8,6 & 2,5 & 2,5 & 1,9 & 0,9 & 3,6 & 148,2 \\
\hline $\mathbf{1 0}$ & 4,3 & 7,9 & 2,5 & 2,8 & 1,5 & & & 146,8 \\
\hline $\mathbf{1 1}$ & 3,7 & 7,6 & 2,4 & 2,6 & 1,5 & 1,1 & 2,8 & 107,8 \\
\hline $\mathbf{1 2}$ & 3,5 & 7,6 & 2,7 & 2,7 & 1,6 & 1,2 & 2,9 & 139,9 \\
\hline $\mathbf{1 3}$ & 4,3 & 7,2 & 2,5 & 2,6 & 1,9 & 1,3 & 3,3 & 142,8 \\
\hline $\mathbf{1 4}$ & 4,3 & 8,2 & 2,8 & 2,4 & 1,6 & 1,2 & 3,7 & 139,5 \\
\hline $\mathbf{1 5}$ & 3,2 & 7,3 & 2,5 & 3,0 & 1,6 & 1,2 & & 150,4 \\
\hline $\mathbf{1 6}$ & 4,2 & 7,9 & 2,7 & 2,6 & 1,6 & & & 132,6 \\
\hline $\mathbf{1 7}$ & 3,7 & 6,9 & 2,4 & 2,5 & 1,7 & 1,4 & 3,9 & 121,3 \\
\hline $\mathbf{1 8}$ & 3,5 & 7,3 & 2,6 & 2,8 & 1,4 & 1,5 & 4,0 & 131,6 \\
\hline $\mathbf{1 9}$ & 3,8 & 7,5 & 2,6 & 2,4 & 1,7 & 1,2 & 2,8 & 101,6 \\
\hline $\mathbf{2 0}$ & 2,6 & 7,2 & 1,9 & 2,7 & 1,5 & & & 110,3 \\
\hline $\mathbf{2 1}$ & 3,0 & 7,4 & 1,9 & 3,0 & 2,0 & 1,2 & 3,1 & 127,2 \\
\hline $\mathbf{2 2}$ & 3,5 & 6,8 & 2,1 & 2,6 & 1,6 & 1,2 & 4,3 & 118,7 \\
\hline $\mathbf{2 3}$ & 3,5 & 7,6 & 2,4 & 1,8 & 1,5 & & 6,0 & 82,8 \\
\hline
\end{tabular}




\begin{tabular}{|c|c|c|c|c|c|c|c|c|}
\hline Núm. inv. & $\mathbf{L P}(\mathbf{c m})$ & $\mathbf{L T}(\mathbf{c m})$ & $\mathbf{A}(\mathbf{c m})$ & $\begin{array}{c}\text { DMax } \\
\mathbf{( c m})\end{array}$ & $\begin{array}{c}\text { Dmin } \\
\mathbf{( c m})\end{array}$ & $\begin{array}{c}\text { Dint } \\
\mathbf{( c m})\end{array}$ & $\mathbf{P}(\mathbf{c m})$ & Masa $\mathbf{( g )}$ \\
\hline $\mathbf{2 4}$ & 2,9 & 7,2 & 2,2 & 2,3 & 1,9 & 1,0 & 5,3 & 85,0 \\
\hline $\mathbf{2 5}$ & 3,6 & 7,6 & 2,6 & 2,7 & 1,5 & 1,3 & 4,6 & 137,9 \\
\hline $\mathbf{2 6}$ & 2,9 & 6,0 & 2,0 & 2,1 & 1,6 & 1,3 & & 85,8 \\
\hline $\mathbf{2 8}$ & 3,6 & 6,4 & 1,9 & 2,1 & 1,7 & & & 76,5 \\
\hline $\mathbf{2 9}$ & 3,9 & 8,4 & 3,1 & 2,8 & 1,5 & 1,5 & 5,9 & 173,4 \\
\hline $\mathbf{3 0}$ & 2,4 & 6,7 & 2,3 & 2,2 & 1,8 & 1,2 & 2,9 & 81,9 \\
\hline $\mathbf{3 1}$ & 2,8 & 5,9 & 1,9 & 1,8 & 1,4 & & & 62,6 \\
\hline $\mathbf{3 2}$ & 3,4 & 5,6 & 2,2 & 2,0 & 1,5 & & & 68,0 \\
\hline $\mathbf{3 3}$ & 2,6 & 6,1 & 2,2 & 2,1 & 1,8 & 1,0 & 2,4 & 90,6 \\
\hline $\mathbf{3 4}$ & 2,5 & 5,6 & 2,1 & 2,0 & 1,5 & 0,9 & 2,7 & 79,9 \\
\hline $\mathbf{3 5}$ & 3,2 & 4,6 & 1,7 & 1,9 & 1,3 & 1,2 & 2,4 & 60,0 \\
\hline $\mathbf{3 6}$ & 2,7 & 4,6 & 1,9 & 1,7 & 1,2 & 0,7 & & 36,9 \\
\hline $\mathbf{3 7}$ & 2,7 & 4,6 & 1,9 & 2,4 & 1,9 & 0,9 & & 72,2 \\
\hline $\mathbf{3 8}$ & 3,1 & 4,1 & 1,6 & & & & & 28,96 \\
\hline $\mathbf{3 9}$ & 2,6 & 3,0 & 1,6 & & 0,9 & & & 27,62 \\
\hline $\mathbf{4 0}$ & 2,6 & 4,3 & 1,8 & & & & & 30,6 \\
\hline $\mathbf{4 1}$ & 3,0 & 5,9 & 1,6 & 1,7 & 1,6 & 1,2 & 3,8 & 44,65 \\
\hline $\mathbf{4 2}$ & 2,4 & 2,1 & 1,6 & & 1,3 & & & 18,83 \\
\hline $\mathbf{4 3}$ & 2,6 & 3,4 & 2,1 & & 1,4 & & & 46,81 \\
\hline $\mathbf{4 5}$ & 4,0 & 6,4 & 2,1 & 2,4 & 0,9 & 1,2 & 3,8 & 93,38 \\
\hline $\mathbf{4 6}$ & 2,4 & 2,5 & 1,2 & & 1,6 & & & 23,41 \\
\hline $\mathbf{4 7}$ & 2,9 & 6,6 & 1,5 & 1,7 & 1,2 & 1,0 & 4,2 & 46,37 \\
\hline $\mathbf{4 8}$ & 3,2 & 6,6 & 2,3 & 1,8 & 1,4 & 1,2 & 4,6 & 69,44 \\
\hline $\mathbf{4 9}$ & 3,2 & 5,9 & 1,7 & 2,0 & 1,3 & 1,3 & 2,9 & 47,37 \\
\hline $\mathbf{5 0}$ & 4,1 & 4,2 & 2,1 & & 1,2 & & & 61,39 \\
\hline $\mathbf{5 1}$ & 3,3 & 4,6 & 2,0 & & & & & 51,65 \\
\hline
\end{tabular}

Sin embargo, hay que remarcar ciertos problemas en la toma de medidas. En algunos casos, por ejemplo, la sección de la punta no era totalmente cuadrada o la del tubo circular, ya fuera por imperfecciones en la fabricación o debido a aplastamientos posteriores. Ante esta situación, se han tomado las medidas de los dos lados, en el caso de las puntas, y los valores más extremos de los diámetros de los tubos. A continuación, se ha utilizado el resultado de sus medias aritméticas de forma convencional. En otras ocasiones, debido al lamentable estado de conservación de algunas piezas, no se tenía la certeza de que la medida que se estaba tomando fuera la correcta, o directamente ha resultado imposible hacerlo. A esto se suma el hecho que la punta 03 tiene adherido un glande de plomo, hecho que obviamente altera el resultado de su masa. En todos estos casos, evidentemente, se ha preferido rechazar la medida para evitar un mayor margen de error en los cálculos.

Además, antes de centrarnos en la propia clasificación, debemos mencionar que ya desde un primer momento se comprobaron algunas diferencias claras entre las piezas. En efecto, parecía que grosso modo se podían establecer dos módulos: uno más grande, con una longitud total en torno a los 10-12 cm y una masa superior a $100 \mathrm{~g}$, y otro más pequeño, de entre 8 y $10 \mathrm{~cm}$ de longitud, y de masa inferior a los $100 \mathrm{~g}$.

\section{ANÁLISIS ESTADÍSTICO Y CLASIFICACIÓN TIPOLÓGICA}

Se ha decidido aplicar el análisis de aglomerados para comprobar si existe algún tipo de agrupación clara entre los proyectiles. El dendrograma resultante (fig. 7) muestra claramente 


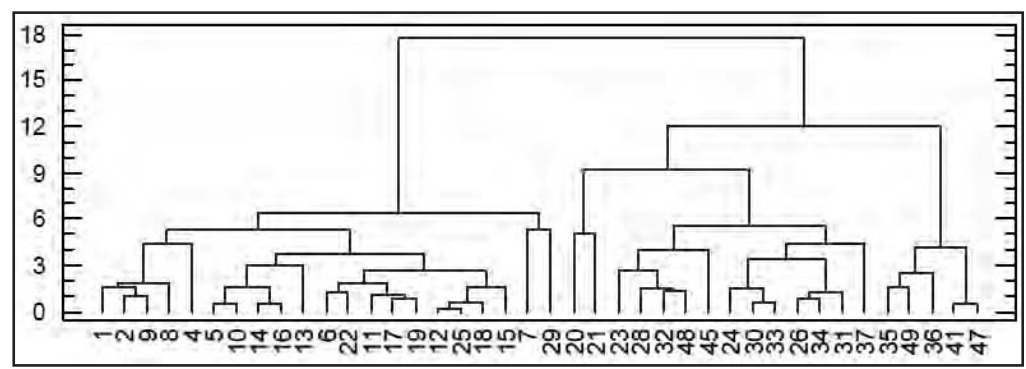

Figura 7. Dendrograma del análisis de aglomerados utilizando un algoritmo basado en la media aritmética y la distancia euclidiana al cuadrado.

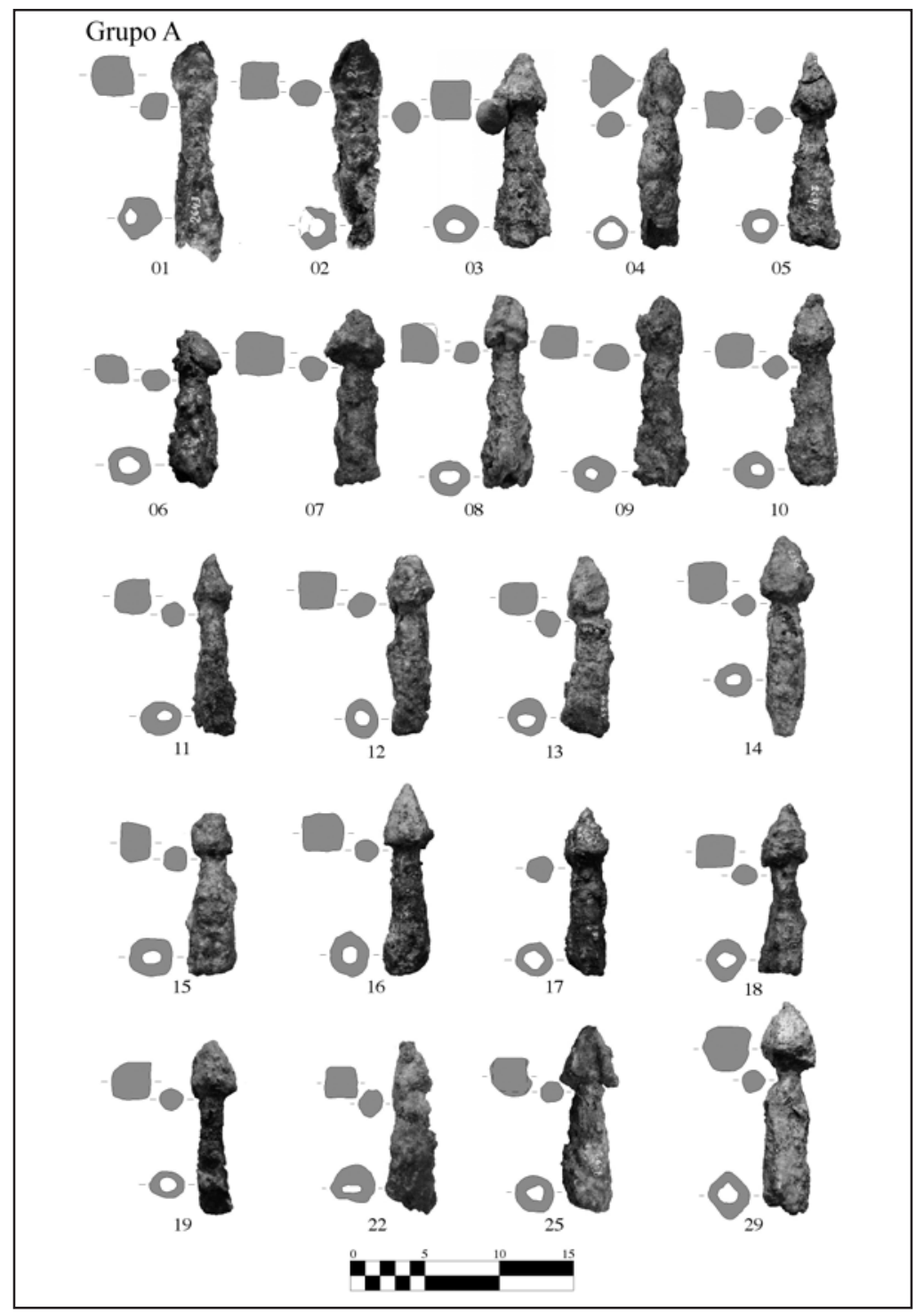

Figura 8. Dibujo y fotografía del Grupo A de pila catapultaria procedentes de Ampurias (realizados por el autor). 


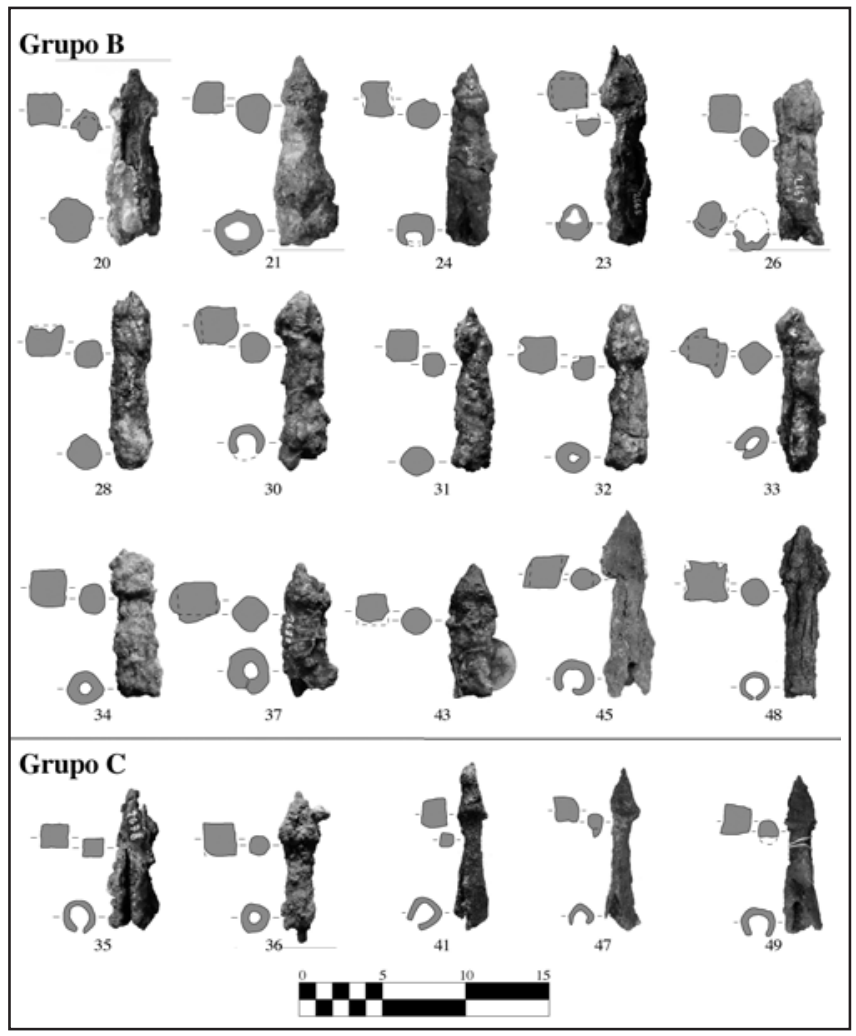

Figura 9. Dibujo y fotografía de los Grupos B y C de pila catapultaria procedentes de Ampurias (realizados por el autor).

la formación de tres grandes grupos. El primero, al que llamaremos Grupo A, está formado por: $01,02,04,05,06,07,08,09,10,11,12,13,14,15,16,17,18,19,22,25,29$ (fig. 8) y se corresponde a grandes rasgos con el modelo de mayores dimensiones que ya apuntábamos antes. El segundo, o Grupo B, lo forman 23, 24, 26, 28, 30, 31, 32, 33, 34 y 48. El Grupo C lo formaría 35, 36, 41, 47 y 49 (fig. 9). Y finalmente, tendríamos a 20 y a 21, que a pesar de vincularse al Grupo B, no se unen hasta mucho más tarde y parecen quedar un poco al margen. Todos estos se corresponden con el grupo de proyectiles más pequeños que ya apuntamos.

Posteriormente, hemos decidido contrastar estos resultados utilizando el análisis de componentes principales. En este caso, hemos optado por representar dos diagramas de dispersión que cruzaran los tres componentes principales con más peso: uno entre el componente 1 y el 2 (fig. 10), y el otro entre el 1 y el 3 (fig. 11). Los resultados de los dos nos confirman la división en tres grupos que nos indicaba el análisis de aglomerados, ya que a pesar de la proximidad entre algunos individuos de diferentes grupos, ninguno de ellos llega a tocar nunca.

En cuanto a los individuos problemáticos 20 y 21, el análisis de componentes principales nos permite proporcionar una respuesta parcial. En efecto, vemos que 20 sólo queda dentro del Grupo B en uno de los dos diagramas, el que cruza el componente 1 con el 2, mientras que 21 queda dentro del Grupo B en uno y del Grupo A en el otro. Por tanto, mediante la estadística podemos intuir su atribución a uno de estos grupos, pero no es posible afirmarlo con seguridad. 


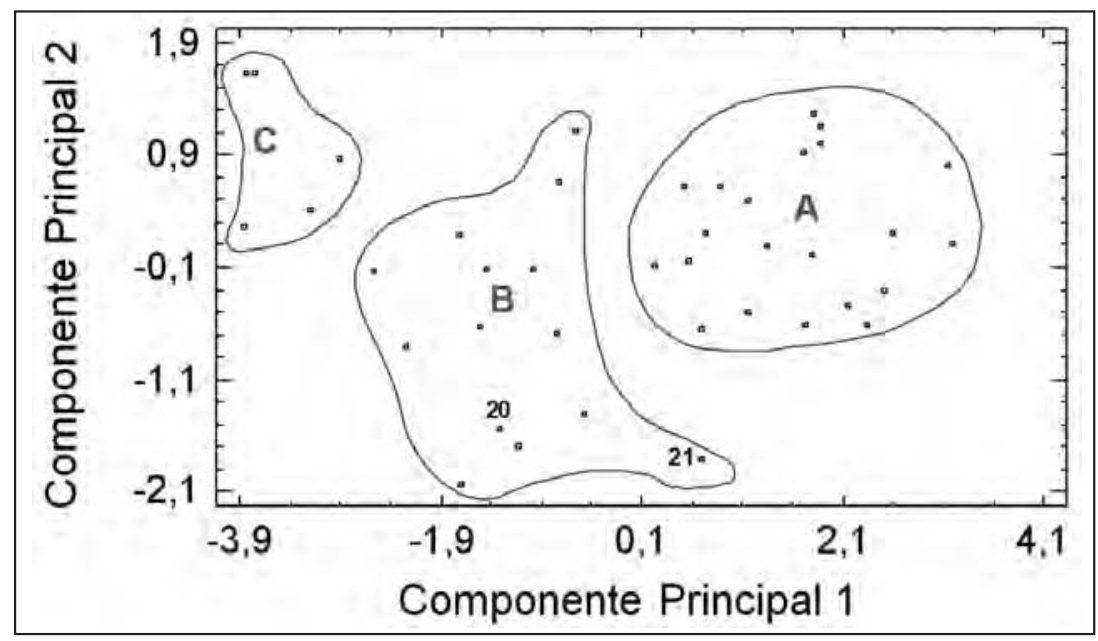

Figura 10. Diagrama de dispersión en función de los componentes principales 1 y 2.

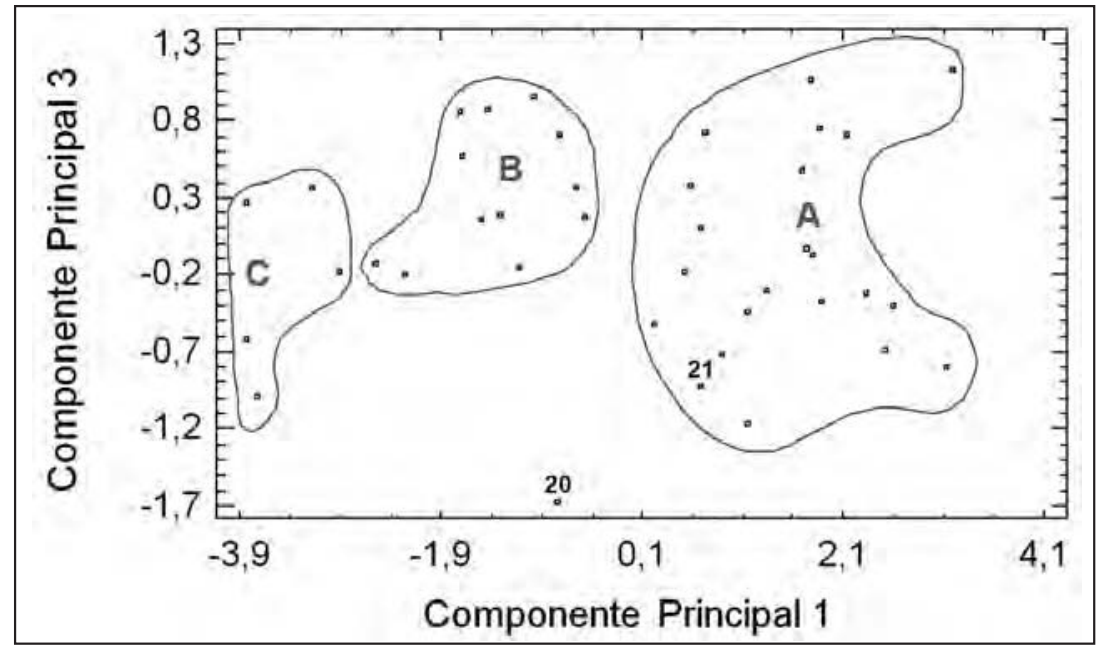

Figura 11. Diagrama de dispersión en función de los componentes principales 1 y 3.

Llegados a este punto, hay que intentar dar una explicación morfológica a la división de los pila catapultaria en estos 3 grupos. Por un lado tendríamos el Grupo A, que se caracteriza por sus mayores dimensiones en términos generales. En efecto, la masa de todos los individuos que seguro pertenece al Grupo A es siempre superior a los $100 \mathrm{~g}$, tiene un promedio de 138,2 g y en dos casos se llega a sobrepasar los $160 \mathrm{~g}$ (8 y 29). En el caso de LP siempre es superior a $3 \mathrm{~cm}$ y se sitúa en torno a los $3,8 \mathrm{~cm}$, y LT torno a 7,8 $\mathrm{cm}$ A y DMax, por su parte, se sitúan entre 2,5 y $3 \mathrm{~cm}$ (con una media de 2,6 y $2,7 \mathrm{~cm}$ respectivamente) y Dmin en torno a $1,7 \mathrm{~cm}$.

Los Grupos B y C son de dimensiones más pequeña, pero en líneas generales siguen respetando las mismas proporciones: relación entre LP y LT de 1 a 2, y A y DMax casi iguales. La diferencia respecto al Grupo A se encuentra, por tanto, en las medidas, no en la forma. Así, la masa es siempre inferior a $100 \mathrm{~g}$ (menos en los casos problemáticos de 20 y 21), LP en torno 
a los $3 \mathrm{~cm}$ y LT en torno a los $6,2 \mathrm{~cm}$. A se sitúa entre 1,5 y $2,5 \mathrm{~cm}$ y DMax entre 1,7 y $3 \mathrm{~cm}$ (ambos con una media de $2 \mathrm{~cm}$ ). Dmin se encuentra en torno a $1,5 \mathrm{~cm}$.

En cambio, las diferencias entre los Grupos B y C sí parecen responder a un aspecto formal más que a uno dimensional. Así, es cierto que las puntas del Grupo B pueden ser relativamente mayores que las del Grupo C, pero sobre todo son mucho más macizas. En efecto, aunque las longitudes de ambos grupos son muy similares, los proyectiles del Grupo B tienden a tener valores de A, DMax y Dmin superiores. Las puntas del Grupo C, en cambio, son más estrechas, y en cierto modo recuerdan al tipo que M. Feugère (1994: 10) propone ya para época imperial, de más longitud y anchura inferior.

Respecto a 20 y 21 hay que remarcar que sufrieron una recubierta de cera mayor, y como consecuencia sus valores de DMax, Dmin y sobre todo A se pueden haber incrementado muy por encima de las medidas reales. Si tenemos en cuenta esto, podríamos incluirlos también en el Grupo B. De hecho, son muy similares morfológicamente a 24 y 31, individuos que pertenecen claramente a este conjunto.

Desgraciadamente, han quedado fuera del estudio estadístico algunas de las piezas por falta de ciertas medidas: $03,28,38,39,40,42,43,46,48,50$ y 51 . Otras, sin embargo, se pueden encuadrar fácilmente en los grupos que hemos definido, como 03 en el Grupo A, o 28, 43, 48 y 51 en el Grupo B. El resto, sin embargo, tienen el tallo tan erosionado que es imposible distinguir el sistema de enmangue. Por este motivo, no disponemos de uno de los criterios esenciales que definen los pila catapultaria, y en este sentido podría tratarse de dardos encastados mediante espiga, jabalinas, o incluso puntas de pila convencionales (fig. 12).

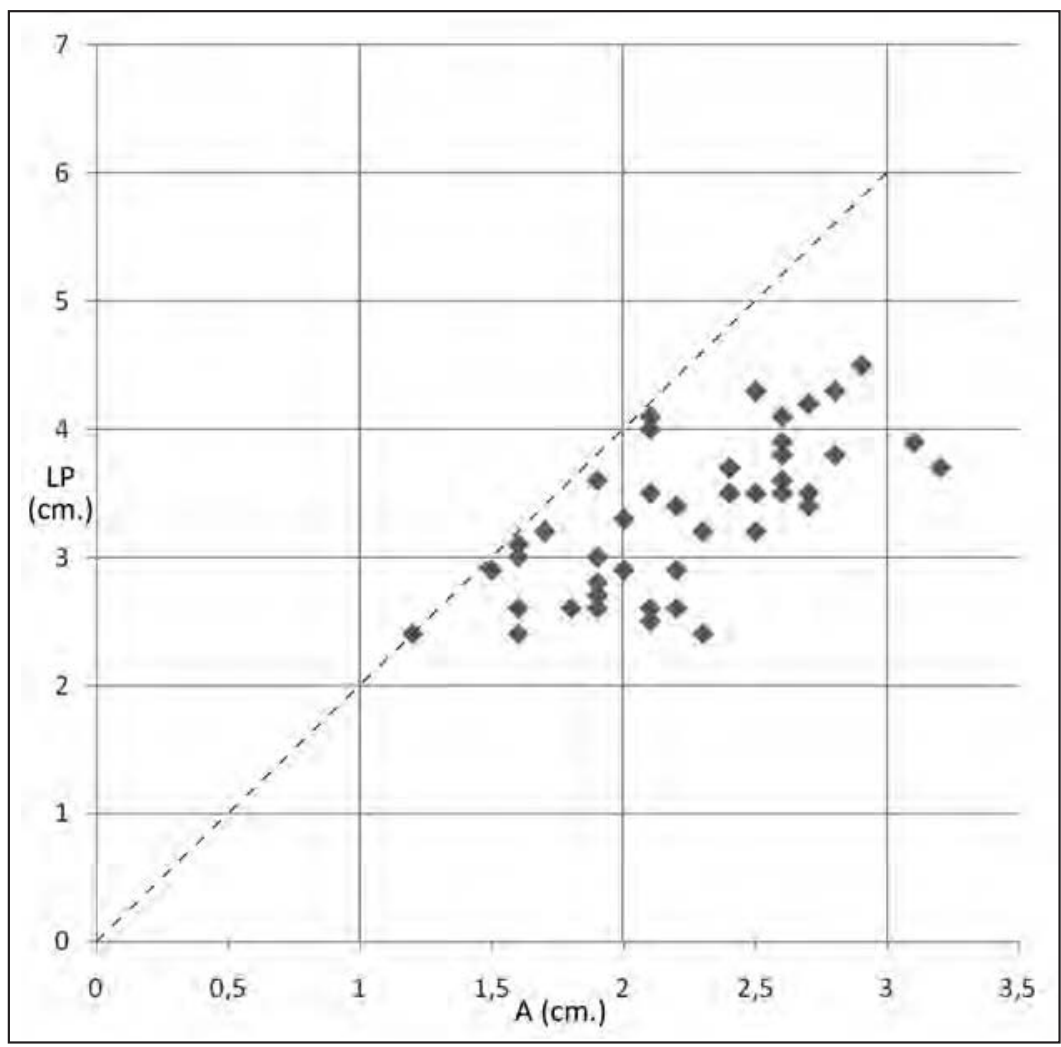

Figura 12. Diagrama de dispersión comparativo de las variables LP y A. 
En definitiva, resulta imposible encuadrarlos en ninguno de los tres grupos, aunque por las medidas de su punta la mayoría se relacionaría con el Grupo C (menos 50, que correspondería más bien al Grupo A).

\section{Propuesta de CAlibres}

Teniendo en cuenta todo lo dicho, consideramos que a pesar de encontrarnos ante tres tipos de proyectiles, sólo podemos hablar de la existencia de dos calibres. Uno mayor, correspondiente al Grupo A, y uno menor, formado por los Grupos B y C, que simplemente representarían variaciones formales. A partir de aquí, podemos plantearnos a qué tipo de máquina correspondería cada uno de ellos. El problema metodológico que detectamos cuando intentamos realizar este razonamiento es el desconocimiento total de la relación entre la longitud de la punta de hierro y la longitud total del proyectil. Los únicos proyectiles que se han conservado íntegramente hasta día de hoy son los descubiertos en Doura Europos, un yacimiento datado de época bajo imperial, por lo que, desgraciadamente, no podemos asegurar que la proporción fuera la misma. De hecho, la opinión más extendida es que durante la época republicana y los inicios de la imperial los pila catapultaria serían más largos (Campbell, 2003: 38).

Como consecuencia, el único mecanismo que nos queda es utilizar la información que nos proporciona el capitulum de catapulta descubierto en la neápolis ampuritana. En efecto, podemos suponer que estaba previsto que la máquina disparara al menos algunos de los proyectiles con los que apareció. Así pues, si tenemos en cuenta que los diámetros internos de los modioli de dicha catapulta miden $8,1 \mathrm{~cm}$, podemos deducir que los proyectiles que dispararía medirían unos $72,9 \mathrm{~cm}^{12}$

Esto los acerca mucho a los tres palmos $(695 \mathrm{~mm})$, un calibre, que junto los dos codos (925 mm), sería uno de las más habituales entre las catapultae de tipo scorpio (Schramm, 1918; Marsden, 1969: 86). En este sentido podemos apoyarnos en el hecho de que las otras catapultae de la península se acercan hasta cierto punto a estos calibres. Así, los modioli de Caminreal, miden 8,2 y 8,4 cm (Vicente, Puntero y Ezquerra, 1997: 170-175), muy similares a los de Ampurias, y por lo tanto, próximos a los de un scorpio de tres palmos. Las dos de Azaila, en cambio, serían un poco más grandes: la aparecida en «la casa del jefe» tiene un modiolus de $9,4 \mathrm{~cm}$ de diámetro, y para la del templo se calcula un agujero de unos $10 \mathrm{~cm}$. Estas medidas, por tanto, las acercarían efectivamente a los dos codos (García Díez, 2002: 298).

A partir de este punto, no podemos deducir de ninguna manera cuál de los dos calibres documentados en el caso de los pila catapultaría de Ampurias se correspondería con el scorpio de tres palmos, aunque teniendo en cuenta lo dicho parecería más lógico suponer que fueran los Grupos B y C, de forma que el Grupo A equivaldría a los dos codos.

\section{PROPUESTA CRONOLÓGICA}

Finalmente, si comparamos las medidas de los pila catapultaria de Ampurias con los de la Galia estudiados por M. Poux (2008: 354-358) nos damos cuenta que el índice LP/A (L/E para Poux) es siempre igual o inferior a 1,5 , acercándose mucho más a los proyectiles cesarianos de yacimientos como Alesia, Gergovia o Uxellodunum, que a los imperiales (fig. 12). Esto nos permite reafirmar la cronología tardorepublicana que les atribuíamos a partir de los

12 Estas medidas se basan en las fórmulas calibración y las dimensiones más usuales para catapultas palintonoi según Filón y presentadas por T. Rihll (2007: 290-291) en forma de tabla. 
datos estratigráficos disponibles. No obstante, si tomamos los valores absolutos de estas dos variables nos damos cuenta que son significativamente superiores, aunque este hecho podría atribuirse simplemente al efecto de la capa de cera, que haría aumentar todas las variables de forma proporcional.

\section{ESTUDIO FUNCIONAL DE LAS EVIDENCIAS DE ARTILLERÍA}

Para terminar el análisis de estos proyectiles proponemos ahora un estudio funcional de los mismos. Este se presenta divido según tres tipos de función que hemos podido distinguir para la artillería: dos de ellas militares, defensiva y ofensiva, y una tercera de tipo simbólico, vinculada al mundo funerario.

\section{FUNCIÓN DEFENSIVA}

El conjunto de Ampurias, por su complejidad, nos permite aventurar de forma efectiva qué función desempeñó la artillería en este yacimiento a partir de la interpretación global de los distintos hallazgos en relación con sus estructuras defensivas. Así pues, por un lado se documenta una habitación cercana a la muralla donde se encontrarían almacenados la mayor parte de los proyectiles y la catapulta de Ampurias. Esta habitación, tanto por su situación como por la gran cantidad de materiales hallados, podría interpretarse como un arsenal o un cuerpo de guardia.

Por el otro, vemos como tanto el pilum catapultarium encontrado en la escombrera Martí, como los dos procedentes de las excavaciones del parking aparecieron extramuros, muy próximos al perímetro de la muralla del siglo II a.C. el primero en dirección oeste, y los otros dos hacia el sur, a poco más de $60 \mathrm{~m}$ de la puerta meridional. En consecuencia, podríamos suponer que todos ellos fueron disparados desde las murallas, hecho que constituiría la evidencia de la puesta en práctica de artillería defensiva, y sobre todo, la primera ocasión en que se podría establecer arqueológicamente un vínculo entre una catapulta y los proyectiles que disparó.

A nivel cronológico, vemos como todas las evidencias (exceptuando la última) se sitúan en una horquilla que va de mediados del siglo II a.C. al final de la República, aproximadamente la misma duración que hemos atribuido a la vida útil potencial de la catapulta. Así pues, podemos afirmar que durante este período la muralla dispuso de un sistema defensivo complejo dotado de artillería (como mínimo de catapultae). Realmente, no tenemos ninguna evidencia de la presencia de artillería en el resto de tramos de muralla, pero la lógica nos permite suponer que se habría cubierto todo el perímetro con máquinas similares.

El caso de Tarraco es muy similar, aunque en este caso sólo disponemos de proyectiles intramuros. En función de su posición respecto a una de las puertas de la muralla, podríamos plantearnos que se tratase de otro ámbito que actuaba como arsenal. En éste, de nuevo, se habrían almacenado proyectiles para las catapultae que seguramente serían desplegadas en las murallas en caso de necesidad, protegiendo este tipo de acceso, tal y como parecen indicarnos las troneras de la torre de Minerva.

En tercer lugar, creemos que es posible plantear también este modelo para el yacimiento de Burriac. Es cierto que en este caso la evidencia arqueológica es muy reducida, pero la existencia de artillería en un asentamiento indígena en el que no se documentan niveles de destrucción parece más lógico relacionarla con una presencia menos agresiva y más permanente del ejército romano, aquí visible en el asentamiento de nueva construcción de Ca l'Arnau - Can Mateu. Su función, a nuestro juicio, sería por tanto únicamente defensiva, hecho que explicaría su proximidad a las murallas y debería interpretarse en clave de almacenamiento, como en los casos 
anteriores. De nuevo, además, parece que la instalación de las máquinas de artillería se situaría como mínimo a partir de mediados del siglo II a.C., coincidiendo con reformas en las murallas.

No estamos seguros de que éste fuera el papel de Puigpelat, pues mientras un proyectil apareció en los niveles de fundamentación, los otros dos se encontraron en los de abandono, pero tampoco se documentaron evidencias de destrucción (Díaz, 2009: 89-90). Lo que sí es cierto es que su situación geográfica cercana al Coll de Lilla es muy estratégica. Desde allí, se controla el paso de la vía que conectaría Tarraco con las comarcas del interior, y por tanto, Ilerda y el valle del Ebro, una ruta vital en este período. En este sentido, la disposición de ballistae de pequeño calibre con una función defensiva no sería una teoría descabellada.

\section{FunCIÓN OFENSIVA}

En el caso del Castellet de Banyoles, en cambio, consideramos que hay pruebas suficientes para afirmar el uso ofensivo de la artillería por parte de los romanos que coincidiría con la destrucción violenta del poblado. Para defender esta hipótesis es necesario que repasemos las principales explicaciones y dataciones que se han otorgado al fin de este asentamiento.

De hecho, ya desde el inicio de las excavaciones, en los años 30, la constatación generalizada de niveles de cenizas en todo el yacimiento, junto con el hallazgo de numerosos tesoros ocultos, hizo pensar a sus excavadores en un saqueo y posterior incendio del poblado, y que a partir del análisis de las fuentes, fue datado entre las guerras púnicas y las primeras revueltas indígenas (Serra-Ràfols, 1965). El reestudio de los materiales cerámicos de estas intervenciones ha permitido proponer una datación en torno a 200 a.C. (Asensio et al., 1996). Además, las últimas campañas arqueológicas siguen documentando los mismos niveles de ceniza en un nuevo sector, muy alejado del anterior (Asensio et al., 2005), demostrando así su omnipresencia y reforzando aún más esta fecha.

En relación a las torres pentagonales, en el interior de las cuales se halló el primer conjunto, se ha escrito mucho. El primero en reflexionar sobre este tema fue R. Pallarès (1984 y 1987), que realizó una primera reconstrucción y atribuyó a las torres una filiación griega. Posteriormente, $\mathrm{P}$. Moret (1998 y 2001) se hizo eco de esta posible influencia del mundo helenístico, pero la matizó afirmando que se trataría de una reformulación indígena con una función más bien de prestigio y no tanto defensiva. F. Gràcia (2000 y 2001), por su lado, ha defendido siempre un amplio conocimiento poliorcético por parte de los indígenas, de manera que, según él, este tipo de torre formaría parte de un sistema defensivo complejo que incluiría la disposición de artillería.

Recientemente, P. Moret (2008) ha cambiado su interpretación de las torres, realizando una reconstrucción muy acertada de las mismas, pero planteando también que este tipo de torre incluiría la disposición de artillería en su interior, y por tanto, que los proyectiles encontrados pertenecerían a la misma comunidad ibérica y no a un posible ejército atacante. En nuestro caso, estamos de acuerdo con F. Quesada (2001: 147-149) cuando afirma la inexistencia de evidencias históricas o arqueológicas suficientes para defender el uso de la artillería antes de la llegada de los romanos.

Además, en el caso de los proyectiles de ballista, existen consideraciones de tipo técnico que imposibilitan plantear su uso defensivo por parte de los habitantes del Castellet de Banyoles. En efecto, tenemos que tener en cuenta que las máquinas de artillería de dos brazos, a diferencia de la catapulta convencional de uno sólo (el onager romano) requieren de un disparo directo, por lo que sólo podrían situarse dentro de las torres o de la muralla, y nunca en los pisos superiores o los pasos de ronda debido a su elevado peso. Sin embargo, esto tampoco es posible, pues para disparar proyectiles de entre 8 y 9,5 kg (unas 20 minae) sería necesaria una 
ballista de 5,075 $\mathrm{m}$ de largo x 3,365 $\mathrm{m}$ de ancho ${ }^{13}$, mientras que la habitación interior de las torres mide 4,1 x 4,3 m de lado (Moret, 2008: 199), y en el caso de las habitaciones adosadas a la muralla el espacio es de sólo $2,8 \mathrm{~m}$.

En relación a la datación de las torres, P. Moret (2008: 207-209) sitúa su construcción con posterioridad a la conquista romana, y sobre todo, a la destrucción del resto del poblado a principios del siglo II a.C. Esta destrucción, por otro lado, podrían no haberla causado los romanos, sino algún pueblo ibérico del interior, como los ilergetes o los lacetanos (Moret, 2008: 213). Al contrario, los romanos habrían colaborado en la reconstrucción que supuso la última fase de hábitat del poblado, y a través de la fuerte influencia ejercida por las tropas itálicas, se habrían introducido nuevos conceptos de poliorcética en sus defensas.

No obstante, un estudio en curso de los materiales aparecidos en el interior de las torres y actualmente depositados en el MAC Barcelona, ha documentado la existencia de un número significativo de ánforas greco-itálicas casi enteras procedentes de los niveles de derrumbe. La datación de estos materiales en torno a 200 a.C., sitúa la destrucción de las torres en una fecha que no puede rebajarse más allá del primer cuarto del siglo II a.C., y sobre todo hace impensable una reconstrucción posterior de las mismas ${ }^{14}$.

A todo ello se suma la reciente constatación de un campamento militar romano cercano al poblado, justo al otro lado del istmo que permite el acceso al yacimiento: el Camí del Castellet de Banyoles. La datación del campamento se ha establecido a partir de la cerámica, esencialmente ánfora greco-itálica, y sobre todo de la numismática. La mayor parte de las monedas fueron acuñadas antes del 200 a.C., pero su comparación con el conjunto recuperado en el campamento de la Palma permite datar su amortización a principios del siglo II a.C. (Noguera, 2008: 40-46). La presencia de un contingente militar romano en un contexto cronológico en el que situamos también la destrucción del poblado ibérico no puede ser casual.

En definitiva, creemos que en el caso del Castellet de Banyoles nos encontramos delante de los vestigios de un sitio culminado por asalto (longuinqua oppugnatio), que incluiría el uso ofensivo de artillería, y que evidentemente habría sido la causa de la destrucción del poblado. Éste se dataría en torno a 200 a.C., en algún momento relacionado con las revueltas indígenas que se sucedieron en el área del bajo Ebro hasta el 183 a.C. En todo caso, creemos que es necesario descartar el uso de la artillería de torsión en esta cronología por parte de las comunidades ibéricas.

\section{FUNCIÓN SIMBÓLICA}

Finalmente, encontramos también un caso en que la presencia de proyectiles de artillería no puede explicarse por una función militar. En efecto, los pila catapultaria encontrados en la necrópolis de Les Corts constituyen el único ajuar encontrado en los dos enterramientos mencionados, un hecho insólito que parece no haber interesado a ningún investigador hasta la fecha.

En relación a su función, descartamos de entrada que fueran las armas causantes de su muerte, pues en tal caso habrían sido quemadas junto a los cuerpos y mostrarían algún tipo de evidencia de combustión. Esto nos conduce a pensar que los pila catapultaria constituyeran un atributo, un elemento distintivo de estos individuos en el momento de su muerte, hecho que nos permite identificarlos como dos artilleros, los encargados del uso y el cuidado de este tipo de maquinaria.

A partir de aquí, surge también el interrogante del origen étnico de estos individuos, y por extensión, de todos aquéllos enterrados en Les Corts, un tema ampliamente discutido. En este

13 Vid nota 12

14 Agradecemos a David Asensio, Rafel Jornet y Jaume Noguera, autores de este trabajo, que nos hayan facilitado la información sobre estos materiales. 
sentido, consideramos que el componente bélico de la necrópolis es un elemento clave para su comprensión, tal y como ya apuntaron J. Brugada (1991: 67-71) y posteriormente G. García Jiménez (2006: 152-154), para los que ésta fue la necrópolis utilizada por los soldados encuadrados en el ejército romano alojados en el praesidium establecido en Emporiae. De hecho, es una de sus características principales, ya que se evidenciaron restos de armamento en hasta diez tumbas, mientras que son totalmente inexistentes en el resto de necrópolis ampuritanas.

Desde nuestro punto de vista, y dada la complejidad y disparidad de evidencias arqueológicas, esta necrópolis se debería entender como el lugar de enterramiento de individuos de origen étnico diverso, sin entrar a adjudicarle una identidad concreta. Lo que es innegable es su carácter militar, con un número destacado de enterramientos de guerreros, ya fueran estos soldados itálicos o auxiliares indígenas. En cualquier caso, y teniendo en cuenta la cronología, serían tropas encuadradas dentro de las legiones romanas.

En el caso concreto de estos dos supuestos encargados de la artillería se podría descartar un carácter ibérico, aunque quizás sí uno griego, pues resulta poco plausible plantear un conocimiento de artillería de este nivel para las comunidades locales. No obstante, este hecho permanece totalmente indemostrable a día de hoy.

\section{CONCLUSIONES}

En conclusión, vemos como el estudio de un conjunto de proyectiles de artillería como el del nordeste peninsular puede permitir un acercamiento mayor al estudio de la artillería antigua que con el simple estudio de la maquinaria, como ha sucedido a menudo, especialmente con la aparecida en Ampurias.

Hemos comprobado que a pesar de la dificultad de precisión a nivel cronológico, podemos encuadrar la mayor parte de las evidencias entre la segunda mitad del siglo II a.C. y la primera mitad del I a.C., coincidiendo con la estabilización de los principales recintos fortificados (Ampurias y Tarraco) como bases estratégicas en la retaguardia romana y el establecimiento de bases secundarias en asentamientos ibéricos, como es el caso de Burriac. Las únicas evidencias claras que tenemos de un uso previo de la artillería las encontramos en el Castellet de Banyoles, coincidiendo con el asedio y destrucción de este poblado por parte del ejército romano.

Al mismo tiempo, vemos como en los casos en que la artillería se usa de forma defensiva, los proyectiles nunca aparecen directamente en la muralla, sino en ámbitos cercanos. Esto se debe a que las máquinas no se mantenían montadas y en posición permanentemente, sino que sólo se situaban en posición en caso de ataque, para evitar que los tendones cedieran a causa de una tensión prolongada y se estiraran, hecho que provocaría una reducción de la potencia y la efectividad del tiro.

Así pues, hemos de entender que la ubicación más común de una máquina de artillería y su munición es el almacenaje en el interior del núcleo fortificado, y en ningún caso eso podría indicar la existencia de un enfrentamiento o combate. Por contra, cuando encontramos restos directamente vinculados a las líneas de defensa, podemos empezar a intuir una acción de asedio. Si los proyectiles se relacionan con niveles de destrucción violenta, la asociación ya es muy clara. Finalmente, si estos proyectiles se encuentran fuera de la ciudad y a cierta distancia de las murallas, como sucedía en Ampurias, se puede aventurar que la artillería con función defensiva fue puesta en práctica.

Por otro lado, comprobamos como los pila catapultaria son presentes en todos los yacimientos a los que se atribuye un uso defensivo, mientras que la mayoría de los lithoboloi documentados se concentran en el único yacimiento para el cual proponemos una función ofensiva. Este hecho nos permite apuntar una relación estrecha entre un tipo de artillería y un 
uso o función concretos. Así pues, las ballistae se utilizarían preferentemente en ataque durante asedios, mientras que las catapultae, y en todo caso ballistae de calibre menor, serían más habituales en defensa de fortificaciones.

\section{BIBLIOGRAFÍA}

Almagro, M. (1947-1948): «Hallazgos numismáticos ampuritanos», Ampurias, 9-10, 320-322.

Almagro, M. (1953): Las necrópolis de Ampurias, vol. 1, Barcelona.

Alvarez, R. y Cubero, M. (1999): «Los pila del poblado ibérico de Castellruf», Gladius, 19, 121-142.

Asensio, D., Cela, X. y Ferrer, C (1996): «Els materials ceràmics del poblat ibèric del Castellet de Banyoles (Tivissa). Col·lecció Salvador Vilaseca de Reus», Pyrenae, 27, 163-191.

Asensio, D., Miró, M. y Sanmartí, J. (2005): «Darreres intervencions arqueològiques al Castellet de Banyoles (Tivissa, Ribera d'Ebre): una ciutat ibèrica en el segle III aC», Món Ibèric al Països Catalans (XIII Col·loqui Internacional d'Arqueologia de Puigcerdà), 615-627.

Baatz, D. (1994): Bauten und Katapulten des Römischen Heeres, Mavors Roman Army Researches, 11, Stuttgart.

Baatz, D. (1999): «Katapulte und mechanische Handwaffen des spätrömischen Heeres», J. Oldenstein and O. Gupte Spätromische (eds.), Spätromische Militärausrüstung, Journal of Roman Military Equipment Studies, 10, 137-140.

Ble, E. (2010): Tormenta romana: els projectils d'artilleria romanorepublicans del nord-est de la Península Ibèrica, trabajo final de Máster, Inédito.

Bru, F. M. (1955): Fulls d'història de la vila de Tivissa i del seu territori antic, AYMA, Tarragona.

Brugada, J. (1991): Armes de ferro del Museu Monogràfic d'Empúries, Treball d'Investigació, Universitat Autònoma de Barcelona, Girona, Inédito.

Barberà, J. y Pascual, R., (1979-1980) «Burriac, un yacimiento protohistórico de la costa catalana (Cabrera de Mar, Barcelona)», Ampurias, 41-42, 203-242.

Campbell, D. (2003): Greek and Roman Artillery 399 BC - AD363, Osprey Publishing, Oxford.

Campbell, D. (2006): Besiged. Siege Warfare in the Ancient World, Osprey Publishing, Oxford.

Díaz García, M. (2009): El Castellum de Puigpelat, Biblioteca Tarraco d'arqueologia, 5.

García Jiménez, G. (2006): Entre Iberos y Celtas: Las espadas de tipo La Tène del

Noreste de la Península Ibérica, Anejos de Gladius, 10, Madrid.

Gracia, F. (2000): «Análisis táctico de las fortificaciones ibéricas», Gladius, 20, 131-170.

Gracia, F. (2001): «Sobre fortificaciones ibéricas. El problema de la divergencia respecto al pensamiento único», Gladius, 21, 155-166.

Güell, M. (1993): «Excavació a la plaça dels Àngels (Tarragona)», Documents d'Arqueologia Clàssica, 1, Tarragona, 229-244.

Hauschild, T. (1984-1985): «Excavaciones en la muralla romana de Tarragona», Boletín Arqueológico, $\mathrm{V}, 6-7,11-38$.

Járrega, R. (2004): «Tarraco Scipionum Opus. ¿Escipión fundador de Tarraco?», Butlletí Arqueològic, 26, Tarragona, 23-66.

Luik, M. (2010): «Los hallazgos de armas den los campamentos romanos alrededor de Numancia, en F. Quesada, M. Navarro y F. Cadiou (coord.), De armas, de hombres y de dioses. El papel de las armas en la conquista romana de la Península Ibérica, Gladius, 30, 43-60.

Martín, A. (2004): «Intervencions arqueològiques a Ca l'Arnau- Can Mateu (Cabrera de Mar)», Jornades d'Arqueologia i Paleontologia, 2001, Barcelona, 376-399.

Martín, O. y Rovira, J. (2009): Arquitectura i urbanisme de la part de Tarraco en època republicana i imperial, Reial Societat Arqueològica Tarraconense, Tarragona.

Moret, P. (1998): «Rostros de piedra. Sobre la racionalidad del proyecto arquitectónico de las fortificaciones ibéricas», Los Íberos, príncipes de occidente, 83-92.

Moret, P. (2001): «Del buen uso de las murallas ibéricas», Gladius, 21, 137-144.

Moret, P. (2008): «A propos du Castellet de Banyoles et Philon de Byzance: une nécessaire palinodie», Salduie, 8, 193-216. 
Noguera, J. (2008): «Los inicios de la conquista romana de Iberia: los campamentos de campaña del curso inferior del río Ebro», Archivo Español de Arqueología, 81, 31-48.

Noguera, J. (2009): «Los campamentos romanos en el curso inferior del río Ebro durante la Segunda Guerra Púnica», in Á. Morillo (ed.), 20th International Congress of Roman Frontier Studies (León, 2006), Anejos de Gladius, 13, 329-338.

Pallarès, C. (1984): «El sistema defensivo frontal del Castellet de Banyoles, Tivissa, Ribera d'Ebre», Pyrenae, 19-20, 113-125.

Pallarès, C. (1987): «Dos elements de filiació grega del segle IV a. C. a l'assentament ibèric del Castellet de Banyoles, Tivissa, Ribera d'Ebre», Protohistòria Catalana (VI Col·loqui Internacional d'Arqueologia de Puigcerdà), Puigcerdà, 281-288.

Puig i Cadafalch, J. (1911-12): «Crònica de les excavacions d'Empúries», Anuari de l'Institut d'Estudis Catalans, Barcelona, 671-672.

Quesada, F. (2001): «En torno al análisis táctico de las fortificaciones ibéricas. Algunos puntos de vista alternativos», Gladius, 21, 145-154.

Quesada, F. (2007): «Asedio, sitio, asalto... Aspectos prácticos de la poliorcética en la iberia prerromana», L. Berrocal y P. Moret (eds.), Paisajes fortificados de la Edad del Hierro, Bibliotheca Archaeologica Hispana, 28, Madrid, 75-98.

Poux, M. (2008): «L'empreinte du militaire césarien dans les faciès mobiliers de La Tène finale. Caractérisation, chronologie et duffusion de ses principaux marqueurs», M. Poux (dir.), Sur les traces de César. Militaria tardo-républicains en contexte gaulois. Actes de la table ronde de Bibracte (Gluxen-Glenne, 17 octobre 2002), Bibracte, 14, 299-432.

Rihll, T. (2007): The Catapult. A History, Westholme Publishing, Yardley, Pennsylvania.

Russo, F. (2004): L'artiglieria delle legioni romane, Roma.

Sáez, R. (2005): Artillería y poliorcética en el mundo grecorromano, Anejos de Gladius, 8, Madrid.

Sáez, R. (2009): «Evidencias arqueológicas de la poliorcética en la Península ibérica», 20th International Congress of Roman Frontier Studies (León, 2006), Anejos de Gladius, 13, Madrid, 1079-1088.

Sanmartí, E. y Nolla, J. M. (1986): «La datation de la partie centrale du rempart méridional d’Emporion (L'Escala, Alt Empordà, Catalogne)», Documents d'Archéologie Méridionale, 9, 81-110.

Serra-Ràfols, J. (1941): «El poblado ibérico del Castellet de Banyoles (Tivissa-Bajo Ebro)», Ampurias 3, 15-34.

Serra-Ràfols, J. (1965): «La destrucción del poblado ibérico del Castellet de Banyoles de Tivissa (Bajo Ebro)», Ampurias, 26-27, 105-117.

Sievers, S. (1997): «Les armes d'Osuna», Antiquités de l’Espagne, Paris, 58-71.

Sievers, S. (2001): «Les armes d'Alesia», en M. Reddé y S. von Schnurbein (ed.), Alésia: fouilles et recherches franco-allemandes sur les travaux militaires romains autour du Mont-Auxois: 1991-1997, Mémoires de l'académie des inscriptions et belles-lettres, tome XXII, vol. 1, Paris.

Tarradell-Font, N. y Noguera J. (2009): «Avance al estudio de las monedas del Camí del Castellet de Banyoles (Tivissa, Tarragona)», A. Árevalo (ed.), Actas XIII Congreso Nacional de Numismática «Moneda y Arqueología», Cádiz, 22-24 de octubre de 2007, tomo I, 143-161.

Vicente Redón, J., Punter, M. P. y Ezquerra, B. (1997): «La catapulta tardorepublicana y otro equipamiento militar de "La Caridad" (Caminreal, Teruel)», en M. Feugère (ed.), L'équipement militaire et l'armement de la république (IVe-Ier s. avant J.-C.), Journal of Roman Military Equipment Studies, 8, 167-199.

Vilaseca, S., Serra-Ràfols, J. y Brull, L. (1949): Excavaciones del Plan Nacional en el Castellet de Bañolas, de Tivissa (Tarragona), Informes y memorias de la Comisaría general de excavaciones arqueológicas, 20, Madrid.

Zamora, D. (2006-2007): «L'oppidum de Burriac: centre del poder polític de la laietània ibèrica», Laietania, 17, 11-420.

Recibido: 29/06/2011

Aceptado: 01/10/2011 